\title{
Quantifying productivity at landscape scale using remotely-sensed foliar traits and canopy structure
}

Daniel Wieczynski ( $\square$ daniel.wieczynski@gmail.com )

Duke University https://orcid.org/0000-0003-4090-2677

\section{Sandra Diaz}

Universidad Nacional de Córdoba https://orcid.org/0000-0003-0012-4612

\section{Sandra M. Duran}

University of Alberta

Nikolaos Fyllas

University of the Aegean

Norma Salinas

Pontificia Universidad Catolica del Peru

Roberta Martin

Arizona State University

\section{Alexander Shenkin}

University of Oxford https://orcid.org/0000-0003-2358-9367

\section{Miles Silman}

Wake Forest University

\section{Gregory Asner}

Center for Global Discovery and Conservation Science, Arizona State University

\section{Lisa P. Bentley}

Sonoma State University

\section{Yadvinder Malhi}

University of Oxford https://orcid.org/0000-0002-3503-4783

\section{Brian Enquist}

University of Arizona

\section{Van Savage \\ University of California}

\section{Article}

Keywords: canopy structure, forests, net primary productivity, remote sensing canopy functional model

Posted Date: November 2nd, 2020 
DOI: https://doi.org/10.21203/rs.3.rs-98574/v1

License: (c) (1) This work is licensed under a Creative Commons Attribution 4.0 International License. Read Full License 
TITLE: Quantifying productivity at landscape scale using remotely-sensed foliar traits and

canopy structure

(n)

\section{AUTHORS:}

Daniel J. Wieczynski ${ }^{1,2 *}$, Sandra Díaz ${ }^{3}$, Sandra M. Duran ${ }^{4}$, Nikolaos M. Fyllas ${ }^{5}$, Norma Salinas 6 , Roberta Martin ${ }^{7}$, Alexander Shenkin ${ }^{8}$, Miles Silman $^{9}$, Gregory P. Asner ${ }^{7}$, Lisa Patrick Bentley ${ }^{10}$, Yadvinder Malhi ${ }^{8}$, Brian J. Enquist ${ }^{4,11}$, \& Van M. Savage ${ }^{1,11}$

\section{AFFILIATIONS:}

${ }^{1}$ Department of Ecology and Evolutionary Biology, University of California, Los Angeles, 612 Charles E Young Drive South, Los Angeles, California 90095, USA

${ }^{2}$ Department of Biology, Duke University, 130 Science Drive, Durham, NC 27708, USA

${ }^{3}$ Consejo Nacional de Investigaciones Científicas y Técnicas, Instituto Multidisciplinario de Biología Vegetal (IMBIV) and Facultad de Ciencias Exactas, Físicas y Naturales, Universidad Nacional de Córdoba, Córdoba, Casilla de Correo 495, 5000, Córdoba, Argentina

${ }^{4}$ Department of Ecology and Evolutionary Biology, University of Arizona, 1041 E Lowell St Tucson, Arizona 85721, USA

${ }^{5}$ Biodiversity Conservation Laboratory, Department of Environment, University of the Aegean, Mytilene, 81100, Greece

${ }^{6}$ Institute for the Sciences of Nature, Earth and Energy (INTE-PUCP), Pontifical Catholic University of Peru. Av. Universitaria 1801, Lima 15088, Peru

${ }^{7}$ School for Geographical Sciences and Urban Planning and Center for Global Discovery and Conservation Science, Arizona State University, Tempe, AZ 85281, USA

${ }^{8}$ Environmental Change Institute, School of Geography and the Environment, University of Oxford, South Parks Road, Oxford, OX1 3QY, UK

${ }^{9}$ Department of Biology and Center for Energy, Environment, and Sustainability, Wake Forest University, Winston-Salem, NC 27109, USA

${ }^{10}$ Department of Biology, Sonoma State University, 1801 E. Cotati Avenue, Rohnert Park, CA 94928, USA

${ }^{11}$ Santa Fe Institute, 1399 Hyde Park Road, Santa Fe, New Mexico 87501, USA

* Corresponding author 


\section{$37 \quad$ ABSTRACT}

38 Forests are integral to global carbon cycling but are threatened by anthropogenic degradation and

39 climate change. Assessing this global threat has been hindered by a lack of clear, flexible, and

40 easy-to-use productivity models along with a lack of functional trait and productivity data for

41 parameterizing and testing those models. Current productivity models are either extremely

42 complex - requiring up to hundreds of parameters, many sub-models, and considerable

43 computational expense — or rely on statistical trait-growth relationships that can be hard to

44 extrapolate to new systems or climates. Here we provide a simple alternative: a remote sensing

45 canopy functional model (RS-CFM) that uses remotely-sensed foliar traits and canopy structure

46 data to efficiently map productivity at high-resolution and large spatial scales. We test this model

47 by quantifying net primary productivity (NPP) at 0.01 -ha resolution in 30,040 hectares of

48 Peruvian tropical rainforest along a 3,322-m Amazon-to-Andes elevation gradient. Our model

49 predicts local NPP and elevational shifts in NPP much more accurately and in greater detail than

50 a prominent alternative method-NASA's MODIS NPP product. Furthermore, we show how

51 NPP estimates depend on light competition and identify the appropriate spatial resolution for

52 remote productivity estimation. Our framework opens up possibilities to fully harness remote

53 sensing data and reliably scale up from traits to map regional or global productivity in a more

54 direct, efficient, and cost-effective manner. 
61 Forests are essential to the earth's active carbon cycle $e^{1,2}$ but their future is uncertain under the

62 current threats of anthropogenic degradation and climate change, especially in the tropics ${ }^{3-6}$.

63 Accurately predicting the consequences of these global threats will require understanding how

64 plant functional traits scale up to influence whole forest productivity ${ }^{7,8}$. Morphological,

65 architectural, and chemical traits—-such as plant height, biomass, leaf area index (LAI), wood

66 density, leaf mass per unit area (LMA), and leaf foliar chemistry (nitrogen, phosphorus, and

67 carbon content) — directly influence individual plant growth rates and survival and, in turn, forest

68 productivity ${ }^{7,9-15}$. In addition, the collection of functional traits expressed within forests varies

69 substantially with changes in geography and climate ${ }^{8,16-18}$. Directly linking traits with plant

70 growth and mapping shifts in functional composition with changes in environmental conditions

71 are therefore crucial to uncovering the forces driving variation in carbon flux across space and

72 time.

74 Relationships between trait composition and ecosystem processes have been difficult to discern

75 for two main reasons. First, it is challenging to accurately and comprehensively measure the

76 functional composition of forests, especially at large spatial scales and remote or difficult-to-

77 sample locations ${ }^{19}$. Solving this problem is the great promise of remote sensing (RS)

78 technology — using airborne or satellite imaging to collect extensive, high-resolution data at

79 local, regional, or global scales ${ }^{20-26}$. Remote sensing has created a surge of information about the

80 functional characteristics of forests ${ }^{21,24,26,27}$, leading to important ecological insights about foliar

81 chemistry $^{28,29}$, forest canopy structure ${ }^{30,31}$, taxonomic and functional diversity ${ }^{32-36}$, biomass and

82 carbon stocks ${ }^{37,38}$, and relationships between functional traits and productivity ${ }^{39-41}$. These 
83 discoveries have resulted in the current initiatives to integrate remotely-sensed functional trait

84 data with vegetation growth models ${ }^{42-45}$ _ for example, dynamic global vegetation models

85 (DGVMs) like LPJ-DGVM ${ }^{46}$ and ED2 $2^{47}$ - to better assess spatiotemporal variation in carbon

86 storage/flux across scales.

88 The second challenge is that many studies that relate remotely-sensed forest data to productivity 89 do so via either empirical (statistical) models — using proxies of plant growth like chlorophyll ${ }^{48}$, 90 nitrogen ${ }^{39}$, light use efficiency $(\mathrm{LUE})^{41}$, or the normalized difference vegetation index

91 (NDVI) ${ }^{49,50}$ —or DGVMs and individual-based forest simulators that are complex, requiring

92 many parameters and substantial computational power and time $44,45,51-53$. Extrapolating the

93 results of purely empirical models to new systems and climates can be hazardous because they

94 lack mechanistic linkages among traits, plant growth, and productivity. Instead, they rely on

95 statistical relationships between plant growth proxies and productivity within a given dataset ${ }^{42,45}$.

96 DGVMs and forest simulators often require specialized expertise, extensive data inputs, or

97 special access ${ }^{51}$, making them hard to implement or reproduce for most researchers. In such

98 models, functional traits are rarely collected remotely and are usually coarsely represented as

99 plant functional types rather than species- or individual-level traits ${ }^{42,45,53}$. Moreover, competition

100 for light is often only crudely incorporated ${ }^{44,53-55}$.

101

102 Using simpler, more mechanistic growth models that utilize remotely-sensed functional trait data

103 is a complementary alternative to these two approaches that can provide a fundamental basis for

104 understanding which factors are most important for driving variation in productivity. These

105 factors can then be varied within models to estimate productivity in new systems or changes in 
106 productivity with changes in climate or forest composition/structure. As a first step, Enquist et

107 al. ${ }^{9}$ derived a trait-based metabolic scaling model that can be used to estimate whole forest net

108 primary productivity (NPP) based on direct relationships between key functional traits and

109 growth rates in individual trees. Fyllas et al. ${ }^{11}$ extended this model using data collected via

110 conventional ground-based field sampling methods. They found that the key to accurately

111 estimating shifts in forest productivity across elevations is accounting for variation in functional

112 traits and canopy structure (light competition) ${ }^{11}$.

114 Here we introduce a new remote sensing canopy functional model (RS-CFM, Figure 1) that

115 overcomes both data and modeling challenges by merging remotely-sensed functional-trait and

116 canopy-structural data with an updated version of the mechanistic growth model outlined

117 above ${ }^{9,11}$. The RS-CFM has notable advantages over previous approaches. Our model is flexible

118 enough to apply to virtually any region or climate because vegetation growth rates are rooted in

119 direct links between a few key plant traits and metabolism, rather than statistical trait-

120 productivity relationships or the imprecise demography of plant functional types. This means

121 that productivity can be easily quantified across large regions using the rapidly-growing

122 inventory of remotely-sensed functional data. The RS-CFM also uses a light competition

123 function that accounts for continuous variation in biomass and light throughout the canopy-

124 significantly outperforming alternative methods without vertical canopy structure. Finally, the

125 simplicity of the RS-CFM relative to previous approaches makes it faster, easier to manipulate

126 and explore parameter space, easier to clarify relationships between plant traits and productivity,

127 and more accessible such that any individual can run it using their own data on their own 
128 computer (i.e., without a supercomputer). Taken together, these advances will facilitate more

129 accurate, higher-resolution productivity estimates at larger spatial scales and lower costs.

131 We use this framework to evaluate the effects of forest functional composition on variation in

132 NPP along a 3,322-m elevation gradient in Peru. Our study area spans a mean annual

133 temperature gradient of $\sim 15^{\circ} \mathrm{C}$ from the lowland Amazonian rainforest to montane forest in the

134 high Andes. Originally established by the Andes Biodiversity and Ecosystem Research Group

$135(\mathrm{ABERG})^{56}$, this site provides a uniquely rich dataset including ground-based $\mathrm{NPP}^{57}$ and plant

136 functional trait ${ }^{36,57}$ measurements as well as airborne lidar and imaging spectroscopy ${ }^{36,58}$. First,

137 we assess whether our model is able to accurately predict local productivity and elevation shifts

138 in productivity in nine focal forest plots (Plot-scale) by comparing our model results with

139 ground-based NPP measurements ${ }^{57}$ and ground-based NPP estimates using a trait-based growth

140 mode ${ }^{11}$. We then extend this method to quantify NPP in 30,040 hectares of forest surrounding

141 the nine focal plots along this elevation gradient (Landscape-scale). Finally, we compare our

142 results with those from another well-known method that uses remote sensing data collected via

143 satellite and estimates productivity using empirical modeling - NASA's moderate resolution

144 imaging spectroradiometer (MODIS) NPP product (MOD17A3v055) $)^{50}$.

146 Our results demonstrate that remotely-sensed trait data can be reliably scaled up to predict

147 variation in NPP across environmental gradients. This opens up possibilities to take advantage of

148 a rapidly-growing inventory of remote data and fulfill the current need for models that quantify

149 productivity across regions in a more direct, efficient, and cost-effective manner ${ }^{42}$. 


\section{$151 \quad$ RESULTS}

152 Our framework quantifies productivity through four basic steps (Figure 1, see Methods for

153 details). First, airborne remote sensing data were collected by the Global Airborne Observatory

154 using visible-to-shortwave infrared (VSWIR) spectrometry and dual-laser waveform light

155 detection and ranging (LiDAR $)^{58}$. Second, VSWIR images were processed and analyzed using

156 partial least squares regression to estimate average values of leaf mass per unit area (LMA), leaf

157 nitrogen and phosphorus content per unit area ( $\left.\mathrm{N}_{\text {area, }}, \mathrm{P}_{\text {area}}\right)$ for the vegetation within individual

158 RS pixels ${ }^{36,58}$. LMA, $\mathrm{N}_{\text {area, }}$ and $\mathrm{P}_{\text {area }}$ were then used as inputs to calculate leaf photosynthetic

159 rates $\left(\mathrm{A}_{\mathrm{L}}\right)$. For each pixel, LiDAR top-of-canopy height measurements and plot-aggregate

160 allometry ${ }^{59,60}$ were used to estimate total aboveground biomass and leaf-mass allometry ${ }^{11}$ was

161 used to calculate total leaf biomass $\left(\mathrm{M}_{\mathrm{L}}\right)$. Third, to account for vertical heterogeneity in canopy

162 biomass and light availability, individual pixels were divided vertically into 1-m slices, each of

163 which was assigned a unique value for leaf biomass and solar radiation based on vertical biomass

164 and light profiles calculated using ground data. Finally, using our mechanistic plant growth

165 model (RS-CFM), we calculated pixel-level growth rates $\left(\dot{\mathrm{M}}_{\text {pixel }}\right)$ by summing growth estimates

166 across all vertical slices within each pixel at $0.01 \mathrm{ha}$, 1ha, and 100ha spatial resolutions. NPP was

167 then calculated as the average growth rate across all pixels within a given plot or elevation band.

169 We begin by comparing our RS-CFM NPP estimates with ground-based NPP measurements ${ }^{57}$

170 and ground-based model NPP estimates ${ }^{11}$. In general, we found very close agreement between

171 ground- and remote-based NPP (Figures $2 \& S 1$ ). At both the plot- and landscape-scales, our

172 model accurately predicts local (within-elevation) NPP as well as characteristic declines in NPP

173 with increasing elevation, including the leveling off of NPP at high elevations (Figure 2a\&b). 
174 The highest-resolution plot-scale NPP estimates (RS-CFM Plot 0.01ha) performed best (Figures

175 2a\&S1, Table S1), exhibiting a root mean square deviation (RMSD) between measured and

176 predicted NPP of 1.02, lower than all other datasets, even ground-based model estimates (ground

177 model: RMSD=1.28). At the level of individual pixels, growth estimates $\left(\dot{\mathrm{M}}_{\text {pixel }}\right)$ from the RS

178 Plot 0.01 ha dataset also performed best, deviating from ground-based NPP measurements by 179 only $0.26 \mathrm{MgC} \mathrm{ha}^{-1} \mathrm{yr}^{-1}$ on average (Figure 2c, Table S1).

181 Interestingly, we found that NPP estimates are sensitive to the spatial scale and resolution of the

182 remote dataset being used. Within all focal plots/elevations, RS-CFM NPP estimates decline

183 with decreasing pixel resolution (Figure 2a\&b, Table S1). This results in a systematic, downward

184 shift in NPP-elevation trends at lower resolutions, despite the shapes of these trends remaining

185 relatively unchanged. Higher-resolution (0.01ha) plot-scale data produced highly accurate NPP

186 estimates $(\mathrm{RMSD}=1.02)$ while lower-resolution data slightly underestimated productivity

$187(\mathrm{RMSD}=1.59)($ Figure $2 \mathrm{a})$, suggesting that the accuracy of NPP estimates increases with pixel

188 resolution. However, at the landscape scale, intermediate resolution (1ha) NPP estimates are

189 actually closest to NPP measurements (RMSD=1.08) (Figure 2b). Because ground-based NPP

190 measurements were originally collected within the same nine focal plots as our plot-scale remote

191 data, we expect our plot-scale NPP estimates to be more representative of the ground-based NPP

192 measurements used in this study than landscape-scale estimates. Given the positive relationship

193 between pixel resolution and NPP estimate accuracy at the plot-scale, it is possible that higher-

194 resolution (0.01ha) landscape-scale NPP estimates are actually be most representative of overall

195 regional productivity. However, verifying this would require more extensive ground sampling

196 throughout the region. 
198 We compared our approach with NASA's MODIS terrestrial NPP product, an easily accessible

199 alternative method for estimating NPP using remote sensing data. MODIS produces NPP

200 estimates by combining Fraction of Photosynthetically Active Radiation (FPAR) and Leaf Area

201 Index (LAI) data collected via satellite imagery at $1 \mathrm{~km}$ (100ha) spatial resolution with

202 conversion efficiency estimates that vary with plant functional types and climatic conditions ${ }^{49,50}$.

203 For this comparison, we extracted all MODIS NPP data overlapping with our entire airborne

204 dataset, providing total spatial coverage at the landscape scale. MODIS NPP estimates are

205 considerably higher on average than NPP and pixel growth estimates from our model (Figure

206 2b\&d, Figure S1). This result is similar to previous findings that DGVMs also tend to

207 overestimate biomass ${ }^{61}$. MODIS NPP remains relatively constant across elevations except for a

208 dramatic decline at higher elevations, in contrast to gradual declines across all elevations seen at

209 all spatial scales and resolutions using our model (Figure 2b). Moreover, the sharp decline in

210 MODIS NPP estimates occurs exactly where NPP measurements and our model estimates show

211 a leveling off. Interestingly, MODIS NPP estimates were very similar to RS-CFM NPP at the

212 highest elevation studied here (3537m; Figure $2 \mathrm{~b})$, potentially due to the sparseness of the

213 canopy reducing vertical variation in light availability. At the level of individual pixels, MODIS

214 NPP values were substantially higher on average than measured NPP values, exhibiting a mean

215 pixel growth rate deviation of $8.88 \mathrm{MgC} \mathrm{ha}^{-1} \mathrm{yr}^{-1}$ (Figure 2d). Similarly, MODIS NPP estimates

216 were also much higher on average than any of our airborne RS-CFM growth rate estimates. Even

217 at the highest pixel resolution tested here (100ha), RS-CFM estimates (RMSD=1.72) represent a

218 significant improvement over MODIS estimates (RMSD=8.31) (Table S1, Figure S1). 
220 The RS-CFM revealed extensive, fine-scale variation in vegetation growth rates at the level of

221 individual pixels $\left(\dot{\mathrm{M}}_{\text {pixel }}\right)$. We calculated deviations between $\dot{\mathrm{M}}_{\text {pixel }}$ and associated NPP

222 measurements and pooled these data by spatial scale and resolution to examine the overall

223 accuracy and spread of $\dot{\mathrm{M}}_{\text {pixel }}$ values (Figure 2c\&d). As with NPP estimates, mean pixel growth

224 rate deviations increased with pixel resolution. High-resolution ( 0.01 ha) plot-scale $\dot{\mathrm{M}}_{\text {pixel }}$

225 estimates performed best, exhibiting deviations from measured NPP that were only slightly

226 higher on average than those of ground-based NPP estimates ( $\mu=0.26$ and $\mu=0.13 \mathrm{MgC} \mathrm{ha}^{-1} \mathrm{yr}^{-1}$,

227 respectively; Figure 2c). Landscape-scale $\dot{M}_{\text {pixel }}$ estimates also performed well at both 0.01 ha

228 and 1ha resolutions (average deviations of $\mu=0.61$ and $\mu=-0.50 \mathrm{MgC} \mathrm{ha}^{-1} \mathrm{yr}^{-1}$, respectively;

229 Figure 2d). Lower-resolution data resulted in the largest mean pixel growth rate deviations, but

230 this effect was less exaggerated at the landscape scale (Figure 2c\&d). In fact, the mean deviation

231 in $\dot{\mathrm{M}}_{\text {pixel }}$ at 1 ha resolution was much lower at the landscape-scale $(\mu=-0.50)$ than at the plot-scale

$232(\mu=-1.49)$ — which was also reflected in the accuracy of associated NPP estimates (plot-scale

$233 \mathrm{RMSD}=1.59$, landscape-scale $\mathrm{RMSD}=1.08$; Table $\mathrm{S} 1$ )—suggesting that lower resolution remote

234 data may only provide accurate growth/NPP estimates at larger spatial scales. Variation in $\dot{\mathrm{M}}_{\text {pixel }}$

235 deviations also increased with pixel resolution and was substantially higher at the landscape

236 scale (Figure 2c\&d, Table S1), corresponding to wider and more continuous distributions of

237 pixel-level trait values both within and across elevations (Figure S2\&S3).

239 Although smaller pixels are subject to increased uncertainty due to inherent errors associated

240 with fine-scale remote sensing data, it has been shown that 1ha resolution remote data for carbon

241 density estimates exhibit $90 \%$ agreement with ground-based field estimates ${ }^{59,62}$. Conversely,

242 functional richness increases with sampling area ${ }^{63-65}$, meaning that lower resolution remote data 
243 may underestimate trait variation by averaging over larger areas. Therefore, based on this

244 reasoning and our empirical results, we propose more generally that 1 ha-resolution trait and

245 productivity estimates most accurately reflect the true variation in forests, even across different

246 forests and environments. Further evaluating how these opposing forces produce variation in

247 remote trait and productivity estimates will be an interesting area of future study.

249 At all scales and resolutions, variation in pixel growth rates is linked to variation in underlying

250 traits. We performed a multiple regression on the individual trait components of our growth

251 model—pixel-level mean LMA, $\mathrm{N}_{\text {area }}, \mathrm{P}_{\text {area }}, \mathrm{A}_{\mathrm{L}}$, and $\mathrm{M}_{\mathrm{L}}$-against $\dot{\mathrm{M}}_{\text {pixel }}$ values using

252 standardized coefficients to determine which traits had the largest impact on variation in growth

253 rates. At all spatial scales and resolutions, $\mathrm{M}_{\mathrm{L}}, \mathrm{A}_{\mathrm{L}}$, and LMA were the strongest predictors of

254 variance in $\dot{M}_{\text {pixel }}$ while leaf nitrogen and phosphorus content were less influential (e.g.,

255 parameter estimates in the RS-CFM 0.01ha model were: $\mathrm{LMA}=-2.03, \mathrm{~N}_{\text {area }}=0.07, \mathrm{P}_{\text {area }}=0.23$,

$256 \mathrm{~A}_{\mathrm{L}}=2.69$, and $\mathrm{M}_{\mathrm{L}}=2.47$, adjusted $\mathrm{R}^{2}=0.92, \mathrm{p}<10^{-5}$; see Table S2). Trait distributions also shift in

257 position and shape along the elevation gradient (Figures S2\&S3), consistent with shifts reported

258 in previous research in this region ${ }^{11,36}$. However, here we also found associated shifts in the

259 distributions of $\dot{\mathrm{M}}_{\text {pixel }}$ values across elevations (Figure S2). We summarized these shifts by

260 calculating the first four central moments of $\dot{\mathrm{M}}_{\text {pixel }}$ distributions and evaluating both linear and

261 polynomial (quadratic) regressions across elevation (Figure S3). Mean $\dot{\mathrm{M}}_{\text {pixel }}$ values (our

262 measure of NPP) decline significantly with increasing elevation at all spatial scales and

263 resolutions. Variance, skewness and kurtosis in $\dot{\mathrm{M}}_{\text {pixel }}$ distributions tend to increase with

264 elevation. However, evidence for shifts in these higher moments is somewhat limited, except

265 perhaps at the landscape scale. 
267 One of the most crucial and challenging components of our model is the inclusion of vertical

268 heterogeneity in light availability (light competition) (Figure 3). Instead of using a single light

269 value for each pixel, our RS-CFM uses a straightforward method for distributing light

270 continuously throughout the canopy. In order to evaluate the importance of this component, we

271 compared our light model with two alternatives that assume no vertical light gradient. When

272 vertical light profiles are held constant and light is assumed to be fully available throughout the

273 canopy (i.e., no light competition), our model overestimates productivity (Figure 3, "No

274 shading"). However, if we assume that light availability is limited by shading — determined by

275 leaf area index (LAI) — but is not distributed continuously throughout the canopy (as is true in

276 most current carbon models ${ }^{53}$ ), then productivity is substantially underestimated (Figure 3 ,

277 "Average shading"). Accounting for this vertical light gradient avoids the problems with both of

278 the limits above and also considerably improves NPP estimates, regardless of the scale or

279 resolution of remote sensing data (Figure 2). These results are consistent with previous findings ${ }^{11}$

280 that light competition does indeed play an essential role in the distribution of tree growth rates

281 and estimates of overall forest productivity.

283 Estimating growth rates using remote sensing data allows us to create high-resolution

284 productivity maps across large regions at multiple spatial scales (Figure 4). At the plot scale, we

285 find remarkable fine-grain spatial heterogeneity in growth rate estimates both within and across

286 elevations (Figure 4a). Landscape-scale data reveal a strong elevation gradient in productivity as

287 well as substantial local variation around this trend (Figure 4b). Such maps provide precise

288 information about the spatial distributions of traits and vegetation growth, allowing us to more 
accurately measure shifts in productivity with shifts in environmental conditions and to better

290 identify local and regional hotspots in functional diversity and primary production.

\section{DISCUSSION}

293 Here we combined remotely-sensed trait and canopy data with a mechanistic vegetation growth

294 model to accurately and efficiently estimate productivity across large regions and in remote or

295 difficult to sample locations. This method creates NPP maps (Figure 4) in a more

296 straightforward, efficient, and reliable manner than current alternative models (e.g., MODIS

297 NPP; see Figure 2). Our model also exposes fundamental links between traits, canopy structure,

298 and productivity across a broad temperature/elevation gradient, thus illuminating how trait-

299 environment relationships scale up to control ecosystem functioning. This information can be

300 used to better understand the forces governing community assembly, help predict shifts in the

301 composition and function of forests in the future, and inform management and conservation

302 efforts by identifying productivity hotspots at high-resolution.

304 Although a variety of modeling frameworks have been developed to evaluate primary production

305 at large spatial scales, the remote sensing canopy functional model (RS-CFM) presented here

306 breaks from previous approaches in important ways. First, our model explicitly links plant traits

307 with growth, providing a highly flexible framework that can be applied across systems. This is in

308 contrast to previous models that rely on statistical relationships between variables within a

309 particular dataset, making extrapolation and prediction either challenging or impossible ${ }^{42,44,45}$.

310 Second, we incorporate spatial variation in functional composition by collecting trait information

311 directly from remote sensing data at high spatial resolution. Although other models (specifically 
312 DGVMs) often include remotely-sensed climate data, they typically include functional variation

313 via established relationships between climate variables and plant functional types ${ }^{42,45}$.

315 Most importantly, our model provides a simpler alternative — without extensive assumptions or

316 the computational demands of simulations - that provides highly accurate estimates of

317 productivity based on forest functional composition at a given point in time (i.e., without the

318 need for repeated flyovers $\left.{ }^{66}\right)$. Indeed, on a personal laptop computer with 4 CPU cores, it takes

319 only about 30 seconds to estimate productivity for the entire region studied here (30,040 ha) at

320 1ha resolution. This computational efficiency, the mechanistic linkages among traits and

321 productivity, and the rich coverage of spatial data through remote sensing are the main

322 advantages of the RS-CFM.

324 In contrast, DGVMs involve many parameters - sometimes hundreds - that appear throughout 325 several different submodels and subroutines that make numerous assumptions about the 326 processes underlying productivity ${ }^{45,55}$. Moreover, individual-based models track individual trees

327 in a spatially explicit manner that requires lots of information and memory ${ }^{45,51}$. These

328 simulation-based models are also evaluated on very short timescales (e.g., hourly as in ED2 ${ }^{47}$ )

329 and often require "spin-up" periods to equilibrate to initial forest conditions prior to analysis

330 (e.g., 1000 yrs in LPJ-DGVM ${ }^{46}$ ). These models are attractive, largely because of their attention

331 to such details, but the level of detail comes at considerable computational expense. The question

332 is: Does the predictive ability and accuracy of these models justify their computational expense?

333 Indeed, how do we quantify such tradeoffs and what data are available to analyze them? 
335 In addition, our framework is flexible and can be easily generalized by including information

336 from other regions beyond the specific choices and calculations we made here for Peruvian

337 tropical forests. For example, it will be interesting to extend the RS-CFM framework to

338 temperate regions — where functional richness is relatively low ${ }^{17,67}$ —or regions exhibiting strong

339 gradients in other environmental variables, like precipitation or vapor pressure. To estimate

340 biomass within pixels we use an aggregate allometry that relates biomass to canopy heights and

341 elevation specifically for the wet montane forests of southern Peru ${ }^{59}$. However, allometric

342 relationships between canopy height and biomass are known to vary across regions ${ }^{59,68}$, which

343 can be accommodated in our model by altering the underlying biomass allometry accordingly.

344 We also use vertical LAI and biomass profiles derived from ground data in the nine focal plots in

345 this study. These components may also vary with study area and well as the level of disturbance

346 present in a given forest, but could be accounted for by incorporating more sophisticated remote

347 sensing methods that directly measure vertical canopy biomass profiles ${ }^{60,69}$. Additionally, our

348 model assumes that leaf photosynthetic rate depends on leaf functional traits (LMA, N, and P)

349 according to relationships previously established for this region ${ }^{11}$. How these traits interact to

350 influence photosynthesis may also depend on various environmental factors-e.g., temperature

351 and precipitation - that also vary across space, although much of this variation is already

352 contained implicitly in shifts in trait distributions themselves. Nevertheless, incorporating

353 environmental variables as predictors of photosynthetic rate might improve productivity

354 estimation and create a more flexible framework that can be applied to many different systems

355 and extended to predict changes in productivity according to projected changes in climatic

356 conditions in the future. 
358 Remote sensing technology shows great promise for evaluating spatial and temporal variation in

359 forest functional composition and productivity. The remote data used in this study were collected

360 from an aircraft. However, such instruments may soon be available aboard satellites, too, and

361 will be able to collect global-scale data in high-frequency time-series (e.g., as in NASA's

362 MODIS dataset $\left.{ }^{49,50}\right)$. We argue that combining elements of our canopy functional model with

363 increasingly available airborne and satellite remote sensing data has the potential to greatly

364 improve the spatio-temporal acuity of productivity estimates. This information will be especially

365 useful when evaluating the consequences of natural and anthropogenic degradation for the global

366 carbon budget.

368 Climate change and deforestation are expected to alter the spatial distribution of functional traits 369 expressed within forests ${ }^{7,17}$. Our framework provides a mechanistic basis for predicting large-

370 scale changes in ecosystem functioning as a result of these expected future disturbances. A first

371 step toward such predictions might be to analyze time-series of remote sensing trait data to

372 establish relationships between changes in functional composition and changes in climate,

373 natural disturbances, anthropogenic impacts, etc. This information can then be combined with

374 mechanistic, trait-based models like ours and extrapolated based on expected future

375 environmental shifts. Analyzing such changes using high-resolution trait and productivity maps

376 will help decode connections between forest composition and NPP, leading to stronger

377 predictions about climate-induced shifts in carbon dynamics, more precise identification of

378 productivity hotspots, and more effective management strategies in the future. In this way,

379 directly linking productivity with functional traits and forest structure will not only improve our 
380 ability to predict future changes, but will also lead to a deeper understanding of the basic

381 processes driving large-scale patterns in carbon dynamics within and across ecosystems.

\section{METHODS}

\section{Ground-based NPP measurements and estimates}

385 Our ground-based dataset consists of nine 1-ha forest plots situated along a 3322-meter Amazon

386 to Andes elevation transect in Peru established by the Andes Biodiversity and Ecosystem

387 Research Group (ABERG; https://www.andesconservation.org/) and incorporated into the Global

388 Ecosystems Monitoring (GEM) network and the "Challenging Attempt to Measure Biotic

389 Attributes along the Slope of the Andes" (CHAMBASA) project

390 (http://gem.tropicalforests.ox.ac.uk/subprojects/traits-leaf-traits-colle). Data collection methods

391 and ground-based NPP measurements and model estimates are described in detail in the original

392 articles and are summarized here. Ground-based NPP was originally measured and reported by

393 Malhi et al. ${ }^{57}$ for all nine focal plots in the current study. Overall NPP was calculated as an

394 aggregate of multiple key components of the autotrophic carbon cycle, including canopy

395 litterfall, leaf loss to herbivory, aboveground woody productivity, and branch turnover.

397 Fyllas et al. ${ }^{11}$ calculated ground-based NPP estimates with trait data collected using conventional 398 field measurements of individual trees (no remote sensing data). Within each plot, species 399 identity was determined for all stems greater than $10 \mathrm{~cm}$ in diameter at breast height (DBH). For 400 a subset of these individual stems ( 7\%), wood density (WD), leaf dry mass per unit wet area 401 (LMA), leaf nitrogen (N) and phosphorus (P) content per unit area. These data were then 
402 incorporated into an individual-based forest simulator to estimate NPP that uses the same

403 vegetation growth equation as in the current study.

404

405 Here we estimated ground-based NPP using the functional trait dataset from Fyllas et al. ${ }^{11}$ and an 406 updated version of their original vegetation growth modeling framework. NPP $\left(\mathrm{MgC} \mathrm{ha}^{-1} \mathrm{yr}^{-1}\right)$

407 was calculated for each plot by calculating and summing the growth rates of all individual trees 408 within that plot:

409

$$
N P P=\sum \dot{M}_{\text {tree }}
$$

410 where $\dot{M}_{\text {tree }}$ is the whole-plant net biomass growth rate of an individual tree and was calculated

411 based on functional traits using an equation derived by Enquist et al. ${ }^{9}$ :

$$
\dot{M}_{\text {tree }}=\frac{d M_{\text {tree }}}{d t}=\left(\frac{c}{\omega}\right)\left(\frac{1}{L M A}\right) A_{L} M_{L}
$$

413 where $c$ is carbon use efficiency and was previously observed to be constant throughout the 414 study region ${ }^{57}$ ( $c=0.33$, no units), $\omega$ is the whole-plant carbon mass fraction ( $\omega=0.5$, no units), $A_{L}$

415 is leaf area specific photosynthetic rate $\left(\mathrm{gC} \mathrm{m}^{-2} \mathrm{y}^{-1}\right), L M A$ is leaf mass per unit area $\left(\mathrm{g} / \mathrm{cm}^{2}\right)$, and $416 M_{L}$ is the total aboveground biomass of an individual tree that is allocated to leaves $(\mathrm{kg})$. We 417 calculated total leaf biomass per tree $\left(M_{L}\right)$ using allometric scaling ${ }^{11}$ :

$$
M_{L}=0.158 * A G B^{0.707}
$$

419 where total aboveground biomass per tree $(A G B)$ is given by Chave et al. ${ }^{68}$ :

$$
A G B=0.0673\left(W D * D B H^{2} * H\right)^{0.976}
$$

421 where $W D$ is wood density, $D B H$ is diameter at breast height, and $H$ is whole tree height. $H$ was 422 estimated for each tree using ${ }^{11}$ :

$$
H=\exp \left(1.51+\log _{10}(D B H)^{0.84}\right)
$$


424 Net leaf photosynthetic rate $(A l)$ follows a Michaelis-Menten function ${ }^{11}$ :

$$
A_{\text {net }}=\frac{A_{\max } I_{\text {comp }}}{k+I_{\text {comp }}}-R_{d}
$$

426 where $A_{n e t}$ is net leaf photosynthetic rate $\left(\mu \mathrm{mol} \mathrm{m} \mathrm{m}^{-2}\right), A_{\max }$ is the maximum photosynthetic rate $427\left(\mathrm{~A}_{\max }=12.13\right), I_{\text {comp }}$ is irradiance available to each tree after accounting for light extinction (due 428 to light competition among trees), $k$ is the half saturation constant of the photosynthetic light 429 response, and $R_{d}$ is respiration in the light. The total leaf photosynthetic rate $\left(A_{L}\right)$ was calculated 430 by dividing $A_{n e t}$ by $12 \mathrm{~h} / 24 \mathrm{~h}=0.5$ to account for day length, which is roughly invariant at these 431 near-equatorial latitudes. All photosynthesis parameters are in $\mu \mathrm{mol} \mathrm{m} \mathrm{m}^{-2} \mathrm{~s}^{-1}$. For each tree, $A_{\max }, k$, 432 and $R_{d}$ were each calculated as functions of $L M A\left(\mathrm{~g} \mathrm{~m}^{-2}\right), N_{\text {area }}\left(\mathrm{g} \mathrm{m}^{-2}\right)$, and $P_{\text {area }}\left(\mathrm{g} \mathrm{m}^{-2}\right)$

433 according to parameters from an updated version of the multiple linear regression model given 434 by Fyllas et al. ${ }^{11}$ :

$$
\begin{gathered}
A_{\max }=10.25+P * 15.51 \\
k=175.51-0.612 * L M A-104.53 * N+1412.23 * P+0.785 * L M A * N-8.395 * L M A * P \\
R_{d}=-1.004+0.017 * L M A+2.363 * N-16.41 * P-0.015 * L M A * N+0.133 * L M A * P
\end{gathered}
$$

437 The solar irradiance available to each tree after accounting for canopy light extinction ( $\left.I_{\text {comp }}\right)$ is 438 calculated as:

$$
I_{\text {comp }}=I * e^{\left(-0.5 * L A I_{L}\right)}
$$

440 Total irradiance $(I)$ was calculated by first converting total solar radiation measured for each

$441 \operatorname{plot}^{11}\left(S\right.$ in $\left.\mathrm{GJ} \mathrm{m}^{-2} \mathrm{y}^{-1}\right)$ to photosynthetic photon flux density (PPFD) assuming a 0.48

442 photosynthetically active radiation (PAR) to solar short-wave radiation ratio, a total solar

443 radiation to PAR conversion factor of $4.6 \mu \mathrm{mol} \mathrm{J} \mathrm{J}^{-1}$, a total foliage absorbance factor assumed to 444 be $0.75^{70}$, and a GJ m $\mathrm{m}^{-2} \mathrm{y}^{-1}$ to $\mathrm{J} \mathrm{m}^{-2} \mathrm{~s}^{-1}$ conversion factor of 31.7 (3.171e8 s/yr * $\left.1 \mathrm{e} 9 \mathrm{~J} / \mathrm{GJ}\right)$. Thus, 445 total irradiance was calculated as $I=S * 0.48 * 4.6 * 0.75 * 31.7$. Then, light competition was 
446 accounted for according to the Perfect Plasticity Approximation (PPA) ${ }^{52}$, in which the whole

447 canopy is divided into layers that receive some fraction of total solar radiation according to their

448 position in the canopy. Trees are sorted into layers by first estimating the crown area $\left(\mathrm{C}_{\mathrm{A}}\right)$ of

449 each tree using ${ }^{11}$ :

$$
C_{A}=0.696 * D B H^{1.305}
$$

451 All trees within each plot were arranged in descending order according to height and their crown 452 areas were summed until the cumulative crown area equalled the total plot area ${ }^{11}$. The height of 453 the last tree in this summation was determined to be the so-called 'critical height' for layer one $454\left(\mathrm{Z}_{\mathrm{L}=1}^{*}\right)$. Trees taller than $\mathrm{Z}_{\mathrm{L}=1}^{*}$ receive full solar radiation, which was measured daily for each plot 455 and averaged over the course of one full year ${ }^{11}$. Then, beginning with then next tallest tree below 456 this critical height, the process is repeated to determine the critical heights for layers 2,3 , and so 457 on until all trees are accounted for. Trees with height between $\mathrm{Z}_{\mathrm{L}=1}^{*}$ and $\mathrm{Z}_{\mathrm{L}=2}^{*}$, are shaded by the 458 first layer and so on according to Beer's light extinction model with an extinction coefficient $459 \mathrm{~K}=0.5$. The leaf area index for each canopy layer $\left(L A I_{L}\right)$ was calculated as

$$
L A I_{L}=\frac{\sum F_{A}}{P_{A}} *(1-L)
$$

461 where $\sum F_{A}$ is the sum of the foliage areas of all trees within a canopy layer, $P_{A}$ is plot ground 462 area, and $L$ is the canopy layer.

464 For comparison between ground and RS-CFM growth rate estimates (Figure 2c), each 1ha 465 ground plot is considered to be a single 1ha 'pixel'. 
468 Visible-to-shortwave infrared (VSWIR) spectrometry and dual-laser waveform light detection

469 and ranging (LiDAR) data were collected remotely for the 9 focal plots by the Global Airborne

470 Observatory $^{58}$. Each remote sensing (RS) plot is geographically centered over its associated

471 ground plot and is 9ha in size. The raw hyperspectral and lidar data were processed to provide

472 estimates of mean top of canopy height $(\mathrm{TCH}), \mathrm{LMA}, \mathrm{N}$, and $\mathrm{P}$ within $10 \mathrm{~m}^{2}$ pixels $(0.01 \mathrm{ha})$

473 using a previously developed protocol ${ }^{28,36,58}$. Hyperspectral data were shade-masked such that

474 only sunlit portions of the canopies were used to measure spectral profiles. RS trait data were

475 also collected for 30,040 hectares of forest surrounding the 9 focal RS plots. Each landscape-

476 scale RS pixel was assigned to an associated focal plot/elevation according to whichever focal

477 plot was nearest in elevation, creating exclusive elevation bands across the 3344m gradient.

478 0.01ha RS data were aggregated at 1ha resolution for both plot-scale and landscape scale

479 datasets. Additionally, landscape-scale RS data were aggregated at 100ha resolution for direct

480 comparison with NASA MODIS NPP estimates.

481

482 To account for vertical variation in biomass and light availability within remote sensing pixels,

483 we divided each RS pixel into horizontal slices $1 \mathrm{~m}$ in height. Aboveground biomass and solar

484 radiation were then distributed to each slice according functions generated using ground plot data

485 (see below). Because of differences in the methods of height estimation using ground and RS

486 data, height values for all trees (ground data) and RS pixels were converted to their respective

487 height quantiles ( $\left.\mathrm{H}_{\text {quantile}}\right)$, thus allowing us to directly compare the vertical biomass and light

488 profiles of ground and RS data. We also removed any RS pixels with heights that were lower

489 than the minimum tree height available for each associated ground-based focal plot: $9 \mathrm{~m}$ for 
SPD_01; 10m for ACJ_01, ESP_01, TRU_04, WAY_01; 12m for PAN_02, SPD_01, TAM_05;

491 and 13m for TAM_06.

492

493 First, total biomass within each pixel was estimated as a function of top of canopy height (TCH) 494 using plot-aggregate allometric scaling ${ }^{59,60}$. Total aboveground carbon density (ACD) within an $495 \quad$ RS pixel is given by ${ }^{59}$ :

$$
A C D=3.8358 * T C H^{0.2807} * B A^{0.9721} * W D^{1.3763}
$$

497 where $B A$ is the total basal area of all trees within a pixel and is also a function of $T C H^{59}$ :

$$
B A=1.5056 * T C H
$$

499 and $W D$ is average wood density within a pixel which is a function of $T C H^{59}$ and elevation $500 \quad(\text { Elev })^{71}$ :

$$
W D=\left\{\begin{aligned}
0.5881-0.0037 * T C H, & \text { Elev } \leq 400 \\
0.5881-0.0037 * T C H+((\text { Elev }-400) * 0.00005), & \text { Elev }>400
\end{aligned}\right.
$$

$502 A C D$ was converted into total aboveground biomass $(A G B)$ by dividing $A C D$ by the whole-plant 503 carbon mass fraction $\left(\omega=0.48^{59,72}\right)$ :

$$
A G B_{\text {pixel }}=A C D_{\text {pixel }} / \omega
$$

505 Total leaf biomass was estimated for each pixel $\left(M_{L, p i x e l}\right)$ by calculating the fraction of total $A G B$

506 that is leaf biomass (leaf mass fraction $=L M F=M_{L, p i x e l} / A G B$ ) within each ground plot and

507 multiplying by the $A G B$ of each pixel in associated RS plots.

$509 M_{L, p i x e l}$ was then distributed across $1 \mathrm{~m}$ slices within each RS pixel according the vertical

510 distribution of leaf biomass in ground plots. Ground-based vertical leaf biomass distributions

511 were calculated for each ground plot by arranging all trees by height within each plot and

512 calculating the cumulative distribution of leaf biomass across all tree heights (remembering that 
513 these have been converted to height quantiles). For the $i$ th slice within each pixel, leaf biomass

$514\left(M_{L, i}\right)$ was determined by calculating the cumulative leaf biomass up to the height quantile of that

515 slice $\left(H_{\text {quantile }, i}\right)$ and subtracting the cumulative leaf biomass for the slice immediately below the

516 ith slice within that pixel (i-1).

518 Light availability was also distributed across slices within each RS pixel based on the vertical

519 distribution of solar radiation previously calculated for each ground plot. First, $L A I_{L}$ values were

520 calculated as in the ground plots but using an allometric equation from Feldpausch et al. ${ }^{73}$ that

521 estimates tree height as a function of diameter at breast height $(D B H)$ and accounts for variation

522 in plot-level basal area $(B A)$ and mean annual temperature $(M A T)$ across plots (model variant:

523 region-environment-structure (West Amazonia)). Individual tree heights were calculated using

524 individual-level $D B H$ values and plot-level $B A$ and $M A T^{57}$ values. For each plot, trees were

525 sorted by height and an exponential decay model was fit to the $L A I_{L}$ values across all trees, thus

526 allowing us to calculate $L A I$ for each RS slice as a continuous function across all heights with

527 parameter values that are unique to each plot/elevation:

$$
L A I_{\text {slice }}=A s y m+\left(R_{0}-A s y m\right) * \exp \left(-r c * H_{\text {quantile }, \text { adj }}\right)
$$

529 where Asym is the horizontal asymptote, $R_{0}$ is the y-intercept, $r c$ is the rate constant, and

$530 H_{\text {quantile,adj }}$ is the height of the RS slice adjusted such that all RS pixels receive full light at the top

531 (maximum irradiance values varied with elevation according to Fyllas et al. ${ }^{11}$ ) and light decays

532 with increasing $L A I$ at the same rate in each pixel regardless of pixel height. $H_{\text {quantile,adj }}$ therefore

533 adjusts the original height of each RS pixel slice $\left(H_{\text {slice }}\right)$ such that the top of canopy height for a

534 given pixel $\left(\mathrm{TCH}_{\text {pixel }}\right)$ matches the maximum top of canopy height for a given plot/elevation

$535\left(\mathrm{TCH}_{\text {plot/elev }}\right)$ : 


$$
H_{\text {quantile }, \text { adj }}=\left(T C H_{\text {plot } / \text { elev }}-T C H_{\text {pixel }}+H_{\text {slice }}\right) / T C H_{\text {plot } / \text { elev }}
$$

538 In order to evaluate the effect of light availability on NPP predictions, we tested the above model

539 of continuous light extinction against two alternative models without vertical heterogeneity in

540 light availability. For the "average shading" version of the model (Figure 3), we calculated the

541 average $L A I$ across all slices within each individual pixel and assigned this average value to all

542 slices within that pixel. For the "no shading" version of the model, we simply set all LAI values

543 to 0, effectively eliminating all shading and allowing full light throughout the canopy.

545 The rate of change in biomass over time for each pixel slice was calculated using the mean trait

546 values available for each RS pixel (same values used for each slice within a pixel):

$$
\frac{d M_{\text {slice }}}{d t}=\left(\frac{c}{\omega}\right)\left(\frac{1}{L M A}\right) A_{L, \text { slice }} M_{L, \text { slice }}
$$

and total growth rate per pixel is the sum of growth across all slices within that pixel:

$$
\dot{M}_{\text {pixel }}=\frac{d M_{\text {pixel }}}{d t}=\sum \frac{d M_{\text {slice }}}{d t}
$$

550 Finally, total annual plot NPP was calculated by taking the mean value of $\dot{M}_{\text {pixel }}$ across all RS

551 pixels associated with a given plot/elevation:

$$
N P P=\frac{1}{n} \sum \dot{M}_{\text {pixel }}
$$

553 The units for both $\dot{M}_{\text {pixel }}$ and NPP were standardized to $\mathrm{MgC} \mathrm{ha}^{-1} \mathrm{yr}^{-1}$ at all spatial scales and 554 resolutions to enable cross-comparison.

556 To compare our method to an alternative method of estimating NPP using RS data, we collected 557 NPP estimates from NASA's moderate resolution imaging spectroradiometer (MODIS) 
558 terrestrial NPP product (MOD17A3v055) ${ }^{49,50}$. Detailed information about methods of collection,

559 NPP calculation, and pre-analysis for MODIS data are available at the MODIS data website

560 (https://modis.gsfc.nasa.gov/data/dataprod/mod17.php). We gathered all unique MODIS NPP

561 pixels overlapping with our 0.01ha-resolution airborne RS data. MODIS pixels overlapping with

562 airborne RS pixels in multiple elevation bands were added to each elevation for analysis.

563

\section{Trait and $\dot{\mathbf{M}}_{\text {pixel }}$ analyses}

565 Pixel growth rate deviations were calculated by subtracting the associated empirical NPP

566 measurements for a given focal plot/elevation from the RS-CFM model NPP estimates. In order

567 to compare NPP estimates from each dataset with empirically measured NPP, we calculated root 568 mean squared deviations (RMSD) between measured and estimated (predicted) NPP values for 569 each plot/elevation as:

$$
R M S D=\sqrt{E\left(\left(N P P_{\text {measured }}-N P P_{\text {predicted }}\right)^{2}\right)}
$$

572 where $E()$ represents the expected value. To differentiate the contributions of individual RS-

573 CFM growth model components-LMA, $\mathrm{N}_{\text {area }}, \mathrm{P}_{\text {area }}, \mathrm{A}_{\mathrm{L}}$, and $\mathrm{M}_{\mathrm{L}} \longrightarrow$ on pixel-level growth rates

$574\left(\dot{M}_{\text {pixel }}\right)$ we performed a main effects multiple linear regression with standardized coefficients. To 575 produce standardized regression coefficients, we centered and rescaled all independent variables

576 (growth model components) prior to analysis by subtracting the means and dividing by their 577 standard deviations. 
579 We evaluated shifts in the distributions of individual RS-CFM growth model components and $580 \dot{M}_{\text {pixel }}$ values by first calculating the first four central moments of each variable within each

581 plot/elevation:

582

583

584

585

586

587

588

589

590

591

592

593

594

595

596

597

598

599

600

601

602

$$
\text { Mean }=\mu_{x}=\frac{\sum x_{i}}{n}
$$

$$
\text { Variance }=\sigma_{x}^{2}=\frac{\sum\left(x_{i}-\mu_{x}\right)^{2}}{n}
$$

$$
\text { Skewness }=\frac{\sum\left(\frac{x_{i}-\mu_{x}}{\sqrt{\sigma_{x}^{2}}}\right)^{3}}{n}
$$

$$
\text { Kurtosis }=\frac{\sum\left(\frac{x_{i}-\mu_{x}}{\sqrt{\sigma_{x}^{2}}}\right)^{4}}{n}-3
$$

Relationships between the moments of each variable at each spatial scale and resolution were then evaluated using both linear and quadratic regression analyses. In cases where both linear and quadratic models produced significant fits and AIC scores differed by less than 4 points, the linear model was chosen as the best fit model on the basis of parsimony (fewer parameters).

All data analyses and productivity estimations were performed in R version $4.0 .0^{74}$.

\section{ACKNOWLEDGMENTS}

This work was supported by NSF grant DEB1457812 (to B.J.E., L.P.B., G.P.A., and V.M.S.). D.J.W. and V.M.S. were also supported by the James F. McDonnell Complex Systems Scholar Award. This work is a product of the Global Ecosystems Monitoring (GEM) network (gem.tropicalforests.ox.ac.uk), the Andes Biodiversity and Ecosystems Research Group ABERG (andesresearch.org), and the Amazon Forest Inventory Network RAINFOR (www.rainfor.org) 
603 research consortia. The field campaign was funded by grants to Y.M. from the UK Natural

604 Environment Research Council (Grant NE/J023418/1), with additional support from European

605 Research Council advanced investigator grants GEM-TRAITS (321131) and T-FORCES

606 (291585) under the European Union's Seventh Framework Programme (FP7/2007-2013). Plot

607 inventories were supported by funding from the US National Science Foundation Long-Term

608 Research in Environmental Biology program (LTREB; DEB 1754647) and the Gordon and Betty

609 Moore Foundation Andes-Amazon Program. We thank the Servicio Nacional de Áreas Naturales

610 Protegidas por el Estado (SERNANP) and personnel of Manu and Tambopata National Parks for

611 logistical assistance and permission to work in the protected areas. We also thank the Explorers'

612 Inn and the Pontifical Catholic University of Peru, as well as AmazonConservation/ACCA for

613 use of the Tambopata and Wayqecha Research Stations, respectively. We are indebted to

614 Professor Eric Cosio (Pontifical Catholic University of Peru) for assistance with research

615 permissions and sample analysis and storage. Taxonomic work at Carnegie Institution was

616 facilitated by Raul Tupayachi, Felipe Sinca, and Nestor Jaramillo. G.P.A. was supported by the

617 endowment of the Carnegie Institution for Science and a grant from the National Science

618 Foundation (DEB-1146206. Y. M. was also supported by the Jackson Foundation. B.J.E. was

619 also supported by NSF HDR-1934790. Finally, we thank the over 200 young Peruvian scientists

620 and students who have trained and worked tirelessly on this project over the years. 


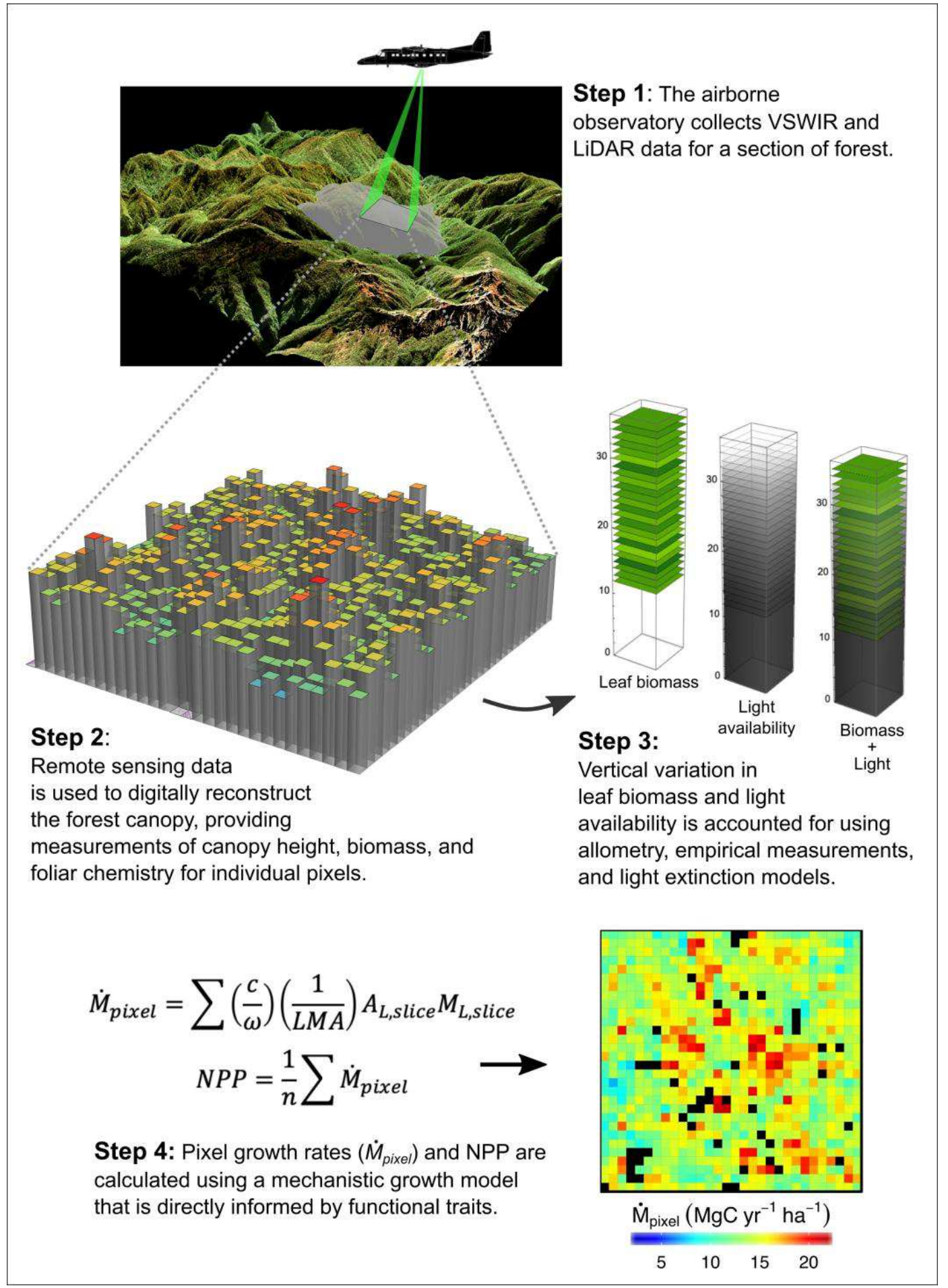

628 Figure 1. Step-by-step process for converting remote sensing data into productivity estimates

629 using our trait-based remote sensing canopy functional model (RS-CFM) framework. Growth 
630 rate estimates for individual remote sensing pixels $\left(\dot{M}_{\text {pixel }}\right)$ are based on key functional traits

631 including carbon use efficiency $(c)$, carbon mass fraction $(\omega)$, leaf mass per unit area $(L M A)$, leaf

632 photosynthetic rate $\left(A_{L}\right)$ - which is a function of $L M A$ and leaf nitrogen $(N)$ and phosphorus $(P)$

633 content — and leaf biomass $\left(M_{L}\right)$. Within each pixel, $A_{L}$ and $M_{L}$ are further subdivided into $1 \mathrm{~m}$

634 pixel slices to account for vertical gradients light and biomass throughout the canopy (Step 3).

635

636

637

638

639

640

641

642

643

644

645

646

647

648

649

650

651

652 


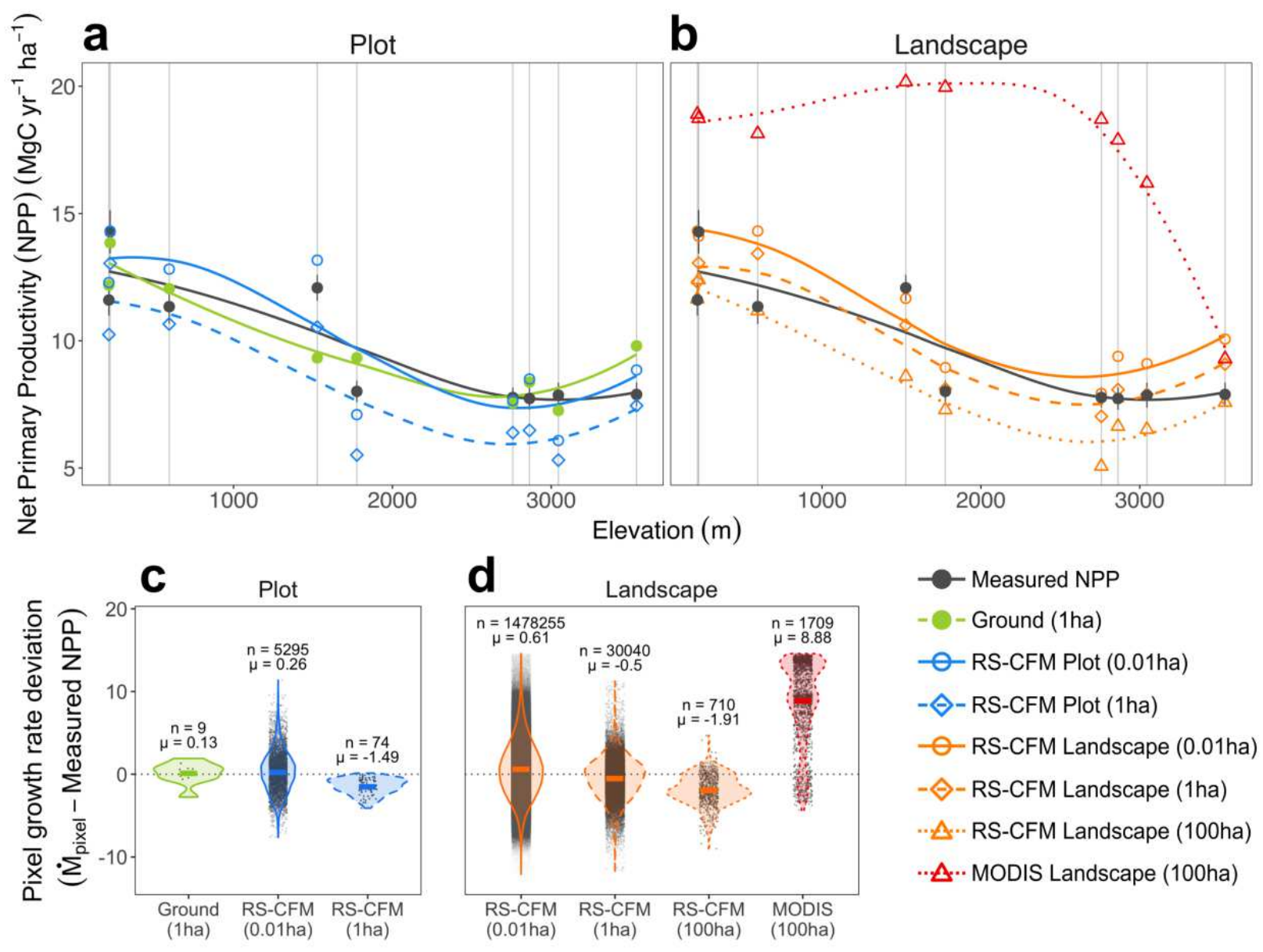

Figure 2. (a-b) Net primary productivity (NPP) and (c-d) individual pixel vegetation growth rate

655 estimates $\left(\dot{M}_{\text {pixel }}\right)$ from ground-based, airborne remote sensing (RS-CFM), and NASA-MODIS

656 NPP models shown at multiple spatial scales (plot and landscape) and resolutions (0.01ha, 1ha,

657 and 100ha). NPP estimates are shown across elevations and compared with ground-based NPP

658 measurements (black) and ground-based NPP model estimates (green) at (a) plot- and (b)

659 landscape-scales. Deviations between pixel growth rate estimates $\left(\dot{M}_{\text {pixel }}\right)$ and NPP

660 measurements at (c) the plot scale and (d) landscape scales. Each gray dot represents the

661 deviation between an individual $\dot{M}_{\text {pixel }}$ estimate and the empirical NPP measurement of its

662 associated focal plot and horizontal bars indicate mean values. Note how both mean and variance

663 in $\dot{M}_{\text {pixel }}$ deviations tend to increase with increasing pixel resolution. 


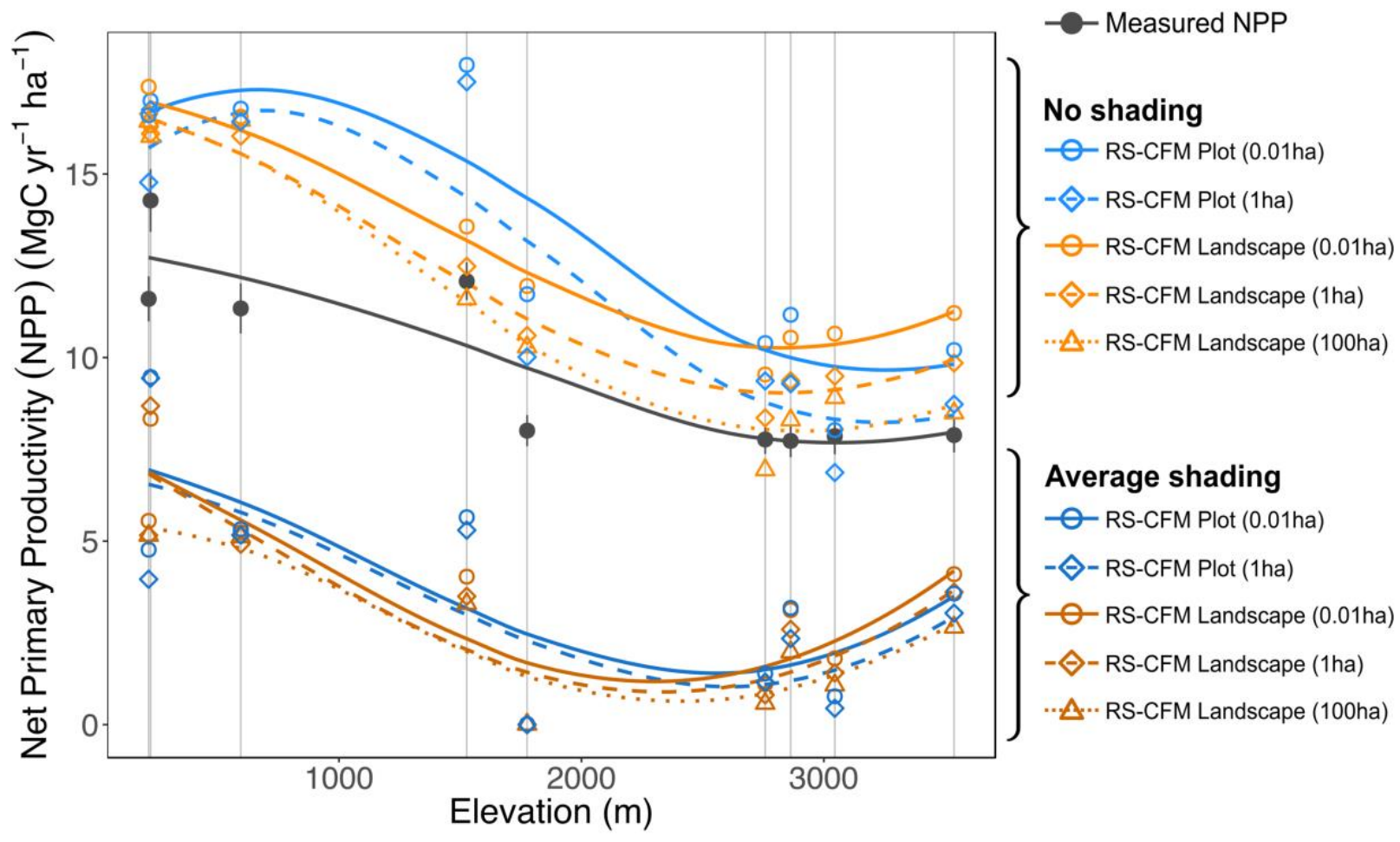

665 Figure 3. Remote sensing productivity estimates (RS-CFM) calculated using alternative canopy

666 shading schemes. "No shading" indicates that light is freely available throughout the canopy and

667 "Average shading" indicates that each vertical canopy slice receives the same amount of light

668 equal to the average throughout a given pixel.

669

670

671

672

673

674

675

676 


\section{a}

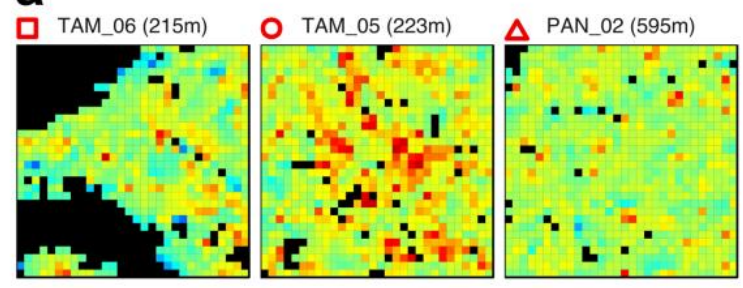

+ SPD_02 (1527m)

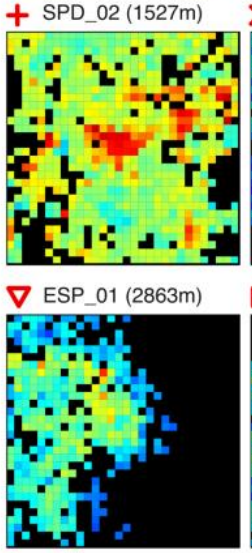

678

679

680

681

682 683 images are no data values.

684

685

686

687

688

689

690

691

684

68

686

b

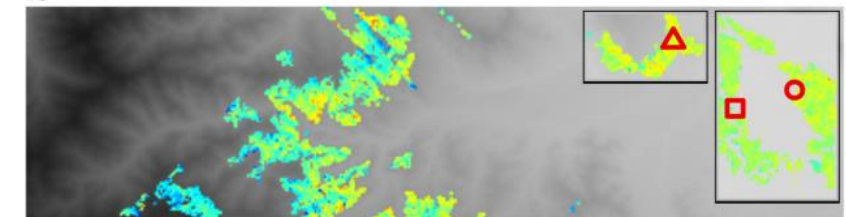

๑TRU_04 (2758m)

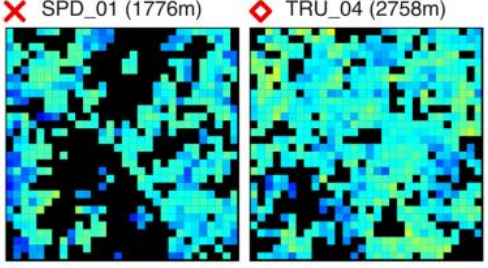

WAY_01 (3045m)

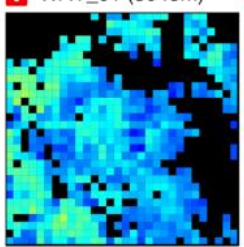

* ACJ_01 (3537m)

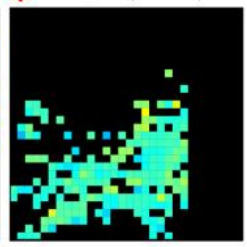

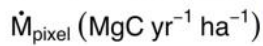

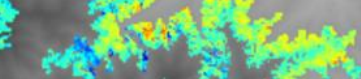
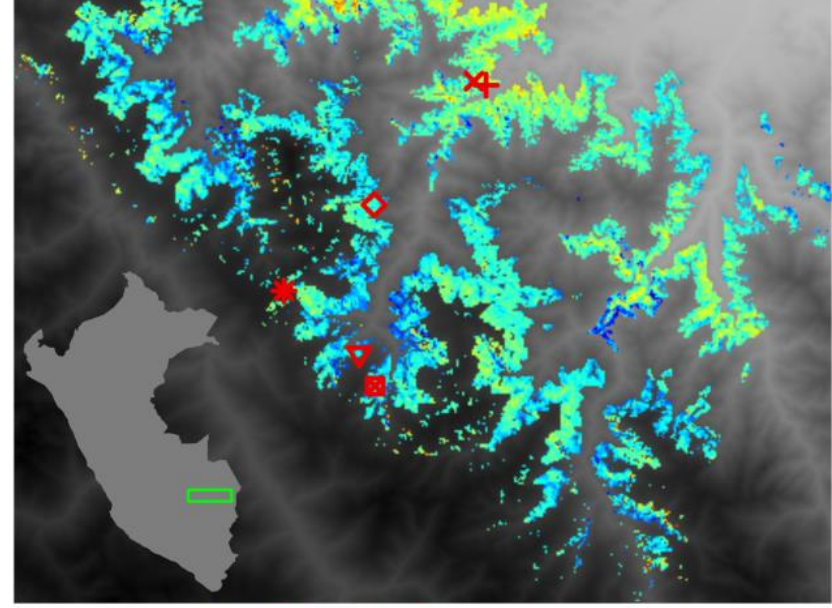

Figure 4. Spatial maps of landscape-scale growth estimates for individual pixels $\left(\dot{M}_{\text {pixel }}\right)$ using our remote sensing canopy functional model (RS-CFM) at (a) 0.01 ha resolution for individual forest plots and (b) 1ha-resolution for 30,040 hectares of forest surrounding the nine focal plots.

Boxes in the upper right corner show areas outside the main plot area. Black pixels in plot-level 


\section{References}

693 1. Field, C. B., Behrenfeld, M. J., Randerson, J. T. \& Falkowski, P. Primary Production of the 694 Biosphere: Integrating Terrestrial and Oceanic Components. Science 281, 237-240 (1998).

695 2. Pan, Y. et al. A Large and Persistent Carbon Sink in the World's Forests. Science 333, $988-$ $696993(2011)$.

697 3. Baccini, A. et al. Tropical forests are a net carbon source based on aboveground

698 measurements of gain and loss. Science 358, 230-234 (2017).

699 4. Mitchard, E. T. A. The tropical forest carbon cycle and climate change. Nature 559, 527-534 $700 \quad$ (2018).

701 5. Schimel, D., Stephens, B. B. \& Fisher, J. B. Effect of increasing CO2 on the terrestrial carbon 702 cycle. Proc. Natl. Acad. Sci. 112, 436-441 (2015).

703 6. Grace, J., Mitchard, E. \& Gloor, E. Perturbations in the carbon budget of the tropics. Glob. $704 \quad$ Change Biol. 20, 3238-3255 (2014).

705 7. Enquist, B. J. et al. Chapter Nine - Scaling from Traits to Ecosystems: Developing a General 706 Trait Driver Theory via Integrating Trait-Based and Metabolic Scaling Theories. in Advances 707 in Ecological Research (eds. Pawar, S., Woodward, G. \& Dell, A. I.) vol. 52 249-318

708 (Academic Press, 2015).

709 8. Violle, C., Reich, P. B., Pacala, S. W., Enquist, B. J. \& Kattge, J. The emergence and promise 710 of functional biogeography. Proc. Natl. Acad. Sci. 111, 13690-13696 (2014).

711 9. Enquist, B. J. et al. A general integrative model for scaling plant growth, carbon flux, and 712 functional trait spectra. Nature 449, 218-222 (2007).

713 10. Wright, I. J. et al. The worldwide leaf economics spectrum. Nature 428, 821-827 (2004). 
714 11. Fyllas, N. M. et al. Solar radiation and functional traits explain the decline of forest 715 primary productivity along a tropical elevation gradient. Ecol. Lett. 20, 730-740 (2017).

716 12. Díaz, S. et al. The global spectrum of plant form and function. Nature 529, 167-171 717 (2016).

718 13. Adler, P. B. et al. Functional traits explain variation in plant life history strategies. Proc. $719 \quad$ Natl. Acad. Sci. 111, 740-745 (2014).

720 14. Funk, J. L. et al. Revisiting the Holy Grail: using plant functional traits to understand 721 ecological processes. Biol. Rev. 92, 1156-1173 (2017).

722 15. Violle, C. et al. Let the concept of trait be functional! Oikos 116, 882-892 (2007).

723 16. Bruelheide, H. et al. Global trait-environment relationships of plant communities. Nat. 724 Ecol. Evol. 2, 1906-1917 (2018).

725 17. Wieczynski, D. J. et al. Climate shapes and shifts functional biodiversity in forests 726 worldwide. Proc. Natl. Acad. Sci. 116, 587-592 (2019).

727 18. Šímová, I. et al. Shifts in trait means and variances in North American tree assemblages: 728 species richness patterns are loosely related to the functional space. Ecography 38, 649-658 729 (2015).

$73019 . \quad$ Newbold, T., Butchart, S. H. M., Şekercioğlu, Ç. H., Purves, D. W. \& Scharlemann, J. P. 731 W. Mapping Functional Traits: Comparing Abundance and Presence-Absence Estimates at 732 Large Spatial Scales. PLOS ONE 7, e44019 (2012).

733 20. Vane, G. \& Goetz, A. F. H. Terrestrial imaging spectroscopy. Remote Sens. Environ. 24, $734 \quad 1-29(1988)$.

735 21. Aplin, P. Remote sensing: ecology. Prog. Phys. Geogr. Earth Environ. 29, 104-113 736 (2005). 
737 22. Ustin, S. L., Roberts, D. A., Gamon, J. A., Asner, G. P. \& Green, R. O. Using Imaging 738 Spectroscopy to Study Ecosystem Processes and Properties. BioScience 54, 523-534 (2004).

739 23. Green, R. O. et al. Imaging Spectroscopy and the Airborne Visible/Infrared Imaging $740 \quad$ Spectrometer (AVIRIS). Remote Sens. Environ. 65, 227-248 (1998).

741 24. Houborg, R., Fisher, J. B. \& Skidmore, A. K. Advances in remote sensing of vegetation 742 function and traits. Int. J. Appl. Earth Obs. Geoinformation 43, 1-6 (2015).

743 25. Gillespie, T. W., Foody, G. M., Rocchini, D., Giorgi, A. P. \& Saatchi, S. Measuring and 744 modelling biodiversity from space. Prog. Phys. Geogr. Earth Environ. 32, 203-221 (2008).

745 26. de Araujo Barbosa, C. C., Atkinson, P. M. \& Dearing, J. A. Remote sensing of ecosystem 746 services: A systematic review. Ecol. Indic. 52, 430-443 (2015).

747 27. Chambers, J. Q. et al. Regional ecosystem structure and function: ecological insights 748 from remote sensing of tropical forests. Trends Ecol. Evol. 22, 414-423 (2007).

749 28. Asner, G. P. \& Martin, R. E. Spectranomics: Emerging science and conservation 750 opportunities at the interface of biodiversity and remote sensing. Glob. Ecol. Conserv. 8, 212$219(2016)$.

752 29. Lausch, A., Erasmi, S., King, D. J., Magdon, P. \& Heurich, M. Understanding Forest 753 Health with Remote Sensing -Part I-A Review of Spectral Traits, Processes and Remote754 Sensing Characteristics. Remote Sens. 8, 1029 (2016).

755 30. Lim, K., Treitz, P., Wulder, M., St-Onge, B. \& Flood, M. LiDAR remote sensing of 756 forest structure. Prog. Phys. Geogr. Earth Environ. 27, 88-106 (2003).

757 31. Zimble, D. A. et al. Characterizing vertical forest structure using small-footprint airborne 758 LiDAR. Remote Sens. Environ. 87, 171-182 (2003). 
759 32. Wang, R. \& Gamon, J. A. Remote sensing of terrestrial plant biodiversity. Remote Sens. $760 \quad$ Environ. 231, 111218 (2019).

761 33. Nagendra, H. Using remote sensing to assess biodiversity. Int. J. Remote Sens. 22, $2377-$ $7622400(2001)$.

763 34. Schneider, F. D. et al. Mapping functional diversity from remotely sensed morphological 764 and physiological forest traits. Nat. Commun. 8, 1-12 (2017).

765 35. Durán, S. M. et al. Informing trait-based ecology by assessing remotely sensed functional 766 diversity across a broad tropical temperature gradient. Sci. Adv. 5, eaaw8114 (2019).

767 36. Asner, G. P. et al. Scale dependence of canopy trait distributions along a tropical forest 768 elevation gradient. New Phytol. 214, 973-988 (2017).

769 37. Goetz, S. \& Dubayah, R. Advances in remote sensing technology and implications for 770 measuring and monitoring forest carbon stocks and change. Carbon Manag. 2, 231-244 $771 \quad$ (2011).

772 38. Lu, D. The potential and challenge of remote sensing-based biomass estimation. Int. J. $773 \quad$ Remote Sens. 27, 1297-1328 (2006).

774 39. Smith, M.-L. et al. Direct estimation of aboveground forest productivity through 775 hyperspectral remote sensing of canopy nitrogen. Ecol. Appl. 12, 1286-1302 (2002).

776 40. Song, C., Dannenberg, M. P. \& Hwang, T. Optical remote sensing of terrestrial 777 ecosystem primary productivity. Prog. Phys. Geogr. Earth Environ. 37, 834-854 (2013).

778 41. Hilker, T., Coops, N. C., Wulder, M. A., Black, T. A. \& Guy, R. D. The use of remote 779 sensing in light use efficiency based models of gross primary production: A review of current 780 status and future requirements. Sci. Total Environ. 404, 411-423 (2008). 
781 42. Boisvenue, C. \& White, J. C. Information Needs of Next-Generation Forest Carbon

782 Models: Opportunities for Remote Sensing Science. Remote Sens. 11, 463 (2019).

783 43. Homolová, L., Malenovský, Z., Clevers, J. G. P. W., García-Santos, G. \& Schaepman, M.

784 E. Review of optical-based remote sensing for plant trait mapping. Ecol. Complex. 15, 1-16

785 (2013).

786 44. Scheiter, S., Langan, L. \& Higgins, S. I. Next-generation dynamic global vegetation 787 models: learning from community ecology. New Phytol. 198, 957-969 (2013).

788 45. Fisher, R. A. et al. Vegetation demographics in Earth System Models: A review of 789 progress and priorities. Glob. Change Biol. 24, 35-54 (2018).

790 46. Sitch, S. et al. Evaluation of ecosystem dynamics, plant geography and terrestrial carbon 791 cycling in the LPJ dynamic global vegetation model. Glob. Change Biol. 9, 161-185 (2003).

792 47. Medvigy, D., Wofsy, S. C., Munger, J. W., Hollinger, D. Y. \& Moorcroft, P. R.

793 Mechanistic scaling of ecosystem function and dynamics in space and time: Ecosystem

794 Demography model version 2. J. Geophys. Res. Biogeosciences 114, (2009).

795 48. Madani, N., Kimball, J. S., Jones, L. A., Parazoo, N. C. \& Guan, K. Global Analysis of 796 Bioclimatic Controls on Ecosystem Productivity Using Satellite Observations of Solar797 Induced Chlorophyll Fluorescence. Remote Sens. 9, 530 (2017).

798 49. Running, S. W. et al. A Continuous Satellite-Derived Measure of Global Terrestrial 799 Primary Production. BioScience 54, 547-560 (2004).

800 50. Zhao, M., Heinsch, F. A., Nemani, R. R. \& Running, S. W. Improvements of the MODIS 801 terrestrial gross and net primary production global data set. Remote Sens. Environ. 95, 164$802176(2005)$. 
803 51. Larocque, G. R. et al. Process-Based Models: A Synthesis of Models and Applications to 804 Address Environmental and Management Issues. Ecological Forest Management Handbook 805 https://www.taylorfrancis.com/ (2016) doi:10.1201/b19150-14.

806 52. Strigul, N., Pristinski, D., Purves, D., Dushoff, J. \& Pacala, S. Scaling from Trees to 807 Forests: Tractable Macroscopic Equations for Forest Dynamics. Ecol. Monogr. 78, 523-545 $808 \quad$ (2008).

809 53. Purves, D. \& Pacala, S. Predictive Models of Forest Dynamics. Science 320, 1452-1453 $810 \quad$ (2008).

811 54. Yang, Y., Zhu, Q., Peng, C., Wang, H. \& Chen, H. From plant functional types to plant 812 functional traits: A new paradigm in modelling global vegetation dynamics. Prog. Phys. 813 Geogr. Earth Environ. 39, 514-535 (2015).

814 55. Quillet, A., Peng, C. \& Garneau, M. Toward dynamic global vegetation models for 815 simulating vegetation-climate interactions and feedbacks: recent developments, limitations, 816 and future challenges. Environ. Rev. 18, 333-353 (2010).

817 56. Andes Biodiversity and Ecosystem Research Group | Using the Andes-Amazon gradient 818 as a laboratory for understanding global change. http://www.andesconservation.org/.

819 57. Malhi, Y. et al. The variation of productivity and its allocation along a tropical elevation 820 gradient: a whole carbon budget perspective. New Phytol. 214, 1019-1032 (2017).

821 58. Asner, G. P., Martin, R. E., Anderson, C. B. \& Knapp, D. E. Quantifying forest canopy 822 traits: Imaging spectroscopy versus field survey. Remote Sens. Environ. 158, 15-27 (2015).

823 59. Asner, G. P. \& Mascaro, J. Mapping tropical forest carbon: Calibrating plot estimates to a 824 simple LiDAR metric. Remote Sens. Environ. 140, 614-624 (2014). 
825 60. Asner, G. P. et al. A universal airborne LiDAR approach for tropical forest carbon 826 mapping. Oecologia 168, 1147-1160 (2012).

827 61. Le Toan, T. et al. Relating Radar Remote Sensing of Biomass to Modelling of Forest 828 Carbon Budgets. Clim. Change 67, 379-402 (2004).

829 62. Mascaro, J., Detto, M., Asner, G. P. \& Muller-Landau, H. C. Evaluating uncertainty in 830 mapping forest carbon with airborne LiDAR. Remote Sens. Environ. 115, 3770-3774 (2011).

831 63. Durán, S. M. et al. Informing trait-based ecology by assessing remotely sensed functional 832 diversity across a broad tropical temperature gradient. Sci. Adv. 5, eaaw8114 (2019).

833 64. Karadimou, E. K., Kallimanis, A. S., Tsiripidis, I. \& Dimopoulos, P. Functional diversity 834 exhibits a diverse relationship with area, even a decreasing one. Sci. Rep. 6, 35420 (2016).

835 65. Schneider, F. D. et al. Mapping functional diversity from remotely sensed morphological 836 and physiological forest traits. Nat. Commun. 8, 1441 (2017).

837 66. Caughlin, T. T. et al. A hyperspectral image can predict tropical tree growth rates in 838 single-species stands. Ecol. Appl. 26, 2369-2375 (2016).

839 67. Lamanna, C. et al. Functional trait space and the latitudinal diversity gradient. Proc. Natl. $840 \quad$ Acad. Sci. 111, 13745-13750 (2014).

841 68. Chave, J. et al. Improved allometric models to estimate the aboveground biomass of 842 tropical trees. Glob. Change Biol. 20, 3177-3190 (2014).

843 69. Drake, J. B., Dubayah, R. O., Knox, R. G., Clark, D. B. \& Blair, J. B. Sensitivity of large844 footprint lidar to canopy structure and biomass in a neotropical rainforest. Remote Sens.

$845 \quad$ Environ. 81, 378-392 (2002). 
846 70. Valladares, F., Skillman, J. B. \& Pearcy, R. W. Convergence in light capture efficiencies

847 among tropical forest understory plants with contrasting crown architectures: a case of

848 morphological compensation. Am. J. Bot. 89, 1275-1284 (2002).

849 71. Asner, G.P. et al. The high-resolution carbon geography of Peru. (2014).

850 72. Martin, A. R. \& Thomas, S. C. A Reassessment of Carbon Content in Tropical Trees.

$851 \quad$ PLOS ONE 6, e23533 (2011).

852 73. Feldpausch, T. R. et al. Height-diameter allometry of tropical forest trees. Biogeosciences

$853 \mathbf{8}, 1081-1106(2011)$.

854 74. R Core Team. R: A language and environment for statistical computing.

\section{Data availability}

857 The raw data that support the findings of this study were used under license from the Global 858 Airborne Observatory at Arizona State University, and so are not publicly available. Data 859 products (productivity estimates) and simulated raw data for use in productivity algorithms are 860 however available at Figshare (upon publication).

\section{Code availability}

863 All custom scripts used in this study are available on GitHub (upon publication).

\section{Author contributions}

866 All authors contributed to the design of the study. R.M. and G.P.A. collected the remote-sensing 867 data. D.J.W. and V.M.S. designed the models and D.J.W. preformed all analyses. D.J.W., 868 V.M.S. wrote the manuscript. All authors contributed to editing the manuscript. 


\begin{tabular}{|c|c|c|c|c|c|c|c|c|}
\hline \multirow[b]{2}{*}{$\begin{array}{r}\text { Plot } \\
\text { (Elevation) }\end{array}$} & \multicolumn{4}{|l|}{ Plot-scale } & \multicolumn{4}{|l|}{ Landscape-scale } \\
\hline & $\begin{array}{r}\text { Measured } \\
\text { NPP }\end{array}$ & $\begin{array}{r}\text { Ground } \\
\text { (1ha) }\end{array}$ & $\begin{array}{l}\text { RS-CFM } \\
\text { (0.01ha) }\end{array}$ & $\begin{array}{r}\text { RS-CFM } \\
\text { (1ha) }\end{array}$ & $\begin{array}{l}\text { RS-CFM } \\
\text { (0.01ha) }\end{array}$ & $\begin{array}{r}\text { RS-CFM } \\
\text { (1ha) }\end{array}$ & $\begin{array}{r}\text { RS-CFM } \\
(100 \mathrm{ha})\end{array}$ & $\begin{array}{l}\text { MODIS } \\
\text { (100ha) }\end{array}$ \\
\hline $\begin{array}{r}\text { TAM_06 } \\
(215 \mathrm{~m})\end{array}$ & 11.60 & $\begin{array}{l}\mathrm{n}=1 \\
12.18 \\
(0.58)\end{array}$ & $\begin{array}{r}\mathrm{n}=600 \\
12.29 \pm 2.67 \\
(0.69)\end{array}$ & $\begin{array}{r}n=8 \\
10.24 \pm 0.9 \\
(-1.36)\end{array}$ & $\begin{array}{r}\mathrm{n}=86711 \\
14.31 \pm 2.81 \\
(2.71)\end{array}$ & $\begin{array}{r}\mathrm{n}=1038 \\
12.31 \pm 1.07 \\
(0.71)\end{array}$ & $\begin{array}{r}\mathrm{n}=32 \\
11.64 \pm 0.62 \\
(0.04)\end{array}$ & $\begin{array}{r}\mathrm{n}=45 \\
18.9 \pm 0.22 \\
(7.3)\end{array}$ \\
\hline $\begin{array}{r}\text { TAM_05 } \\
(223 \mathrm{~m})\end{array}$ & 14.28 & $\begin{array}{r}\mathrm{n}=1 \\
13.85 \\
(-0.43)\end{array}$ & $\begin{array}{r}\mathrm{n}=853 \\
14.31 \pm 2.38 \\
(0.03)\end{array}$ & $\begin{array}{r}n=9 \\
13.04 \pm 0.67 \\
(-1.24)\end{array}$ & $\begin{array}{r}\mathrm{n}=46067 \\
14.11 \pm 2.89 \\
(-0.17)\end{array}$ & $\begin{array}{r}\mathrm{n}=524 \\
13.06 \pm 0.9 \\
(-1.22)\end{array}$ & $\begin{array}{r}n=6 \\
12.39 \pm 0.27 \\
(-1.89)\end{array}$ & $\begin{array}{r}\mathrm{n}=21 \\
18.73 \pm 0.3 \\
(4.45)\end{array}$ \\
\hline $\begin{array}{r}\text { PAN_02 } \\
(595 \mathrm{~m})\end{array}$ & 11.34 & $\begin{array}{l}\mathrm{n}=1 \\
12.05 \\
(0.71)\end{array}$ & $\begin{array}{r}\mathrm{n}=871 \\
12.82 \pm 1.79 \\
(1.48)\end{array}$ & $\begin{array}{r}n=9 \\
10.66 \pm 0.23 \\
(-0.68)\end{array}$ & $\begin{array}{r}\mathrm{n}=35984 \\
14.31 \pm 2.74 \\
(2.97)\end{array}$ & $\begin{array}{r}\mathrm{n}=562 \\
13.42 \pm 1.6 \\
(2.08)\end{array}$ & $\begin{array}{r}\mathrm{n}=17 \\
11.18 \pm 0.56 \\
(-0.16)\end{array}$ & $\begin{array}{r}\mathrm{n}=17 \\
18.14 \pm 2.97 \\
(6.8)\end{array}$ \\
\hline $\begin{array}{l}\text { SPD_02 } \\
(1527 \mathrm{~m})\end{array}$ & 12.08 & $\begin{array}{r}\mathrm{n}=1 \\
9.33 \\
(-2.75)\end{array}$ & $\begin{array}{r}\mathrm{n}=704 \\
13.17 \pm 2.79 \\
(1.09)\end{array}$ & $\begin{array}{r}n=9 \\
10.54 \pm 0.81 \\
(-1.54)\end{array}$ & $\begin{array}{r}\mathrm{n}=465340 \\
11.66 \pm 3.65 \\
(-0.42)\end{array}$ & $\begin{array}{r}\mathrm{n}=9667 \\
10.62 \pm 2.88 \\
(-1.46)\end{array}$ & $\begin{array}{r}n=192 \\
8.6 \pm 1.7 \\
(-3.48)\end{array}$ & $\begin{array}{r}\mathrm{n}=334 \\
20.18 \pm 2.13 \\
(8.1)\end{array}$ \\
\hline $\begin{array}{l}\text { SPD_01 } \\
(1776 \mathrm{~m})\end{array}$ & 8.01 & $\begin{array}{r}\mathrm{n}=1 \\
9.33 \\
(1.32)\end{array}$ & $\begin{array}{r}\mathrm{n}=470 \\
7.1 \pm 1.85 \\
(-0.91)\end{array}$ & $\begin{array}{r}n=9 \\
5.51 \pm 0.75 \\
(-2.5)\end{array}$ & $\begin{array}{r}n=168747 \\
8.95 \pm 2.33 \\
(0.94)\end{array}$ & $\begin{array}{r}\mathrm{n}=3874 \\
8.11 \pm 2 \\
(0.1)\end{array}$ & $\begin{array}{r}n=131 \\
7.29 \pm 1.65 \\
(-0.72)\end{array}$ & $\begin{array}{r}n=252 \\
19.96 \pm 2.55 \\
(11.95)\end{array}$ \\
\hline $\begin{array}{l}\text { TRU_04 } \\
\text { (2758m) }\end{array}$ & 7.77 & $\begin{array}{r}\mathrm{n}=1 \\
7.55 \\
(-0.22)\end{array}$ & $\begin{array}{r}n=656 \\
7.65 \pm 1.89 \\
(-0.12)\end{array}$ & $\begin{array}{r}n=9 \\
6.39 \pm 0.5 \\
(-1.38)\end{array}$ & $\begin{array}{r}\mathrm{n}=303322 \\
7.93 \pm 2.71 \\
(0.16)\end{array}$ & $\begin{array}{r}\mathrm{n}=6046 \\
7.03 \pm 2.05 \\
(-0.74)\end{array}$ & $\begin{array}{r}n=140 \\
5.07 \pm 0.87 \\
(-2.7)\end{array}$ & $\begin{array}{r}\mathrm{n}=313 \\
18.7 \pm 4.37 \\
(10.93)\end{array}$ \\
\hline $\begin{array}{l}\text { ESP_01 } \\
(2863 \mathrm{~m})\end{array}$ & 7.73 & $\begin{array}{r}\mathrm{n}=1 \\
8.38 \\
(0.65)\end{array}$ & $\begin{array}{r}\mathrm{n}=353 \\
8.5 \pm 3 \\
(0.77)\end{array}$ & $\begin{array}{r}n=6 \\
6.48 \pm 1.47 \\
(-1.25)\end{array}$ & $\begin{array}{r}\mathrm{n}=180731 \\
9.39 \pm 3.56 \\
(1.66)\end{array}$ & $\begin{array}{r}\mathrm{n}=3589 \\
8.08 \pm 2.5 \\
(0.35)\end{array}$ & $\begin{array}{r}n=42 \\
6.64 \pm 1.19 \\
(-1.09)\end{array}$ & $\begin{array}{r}\mathrm{n}=285 \\
17.88 \pm 4.76 \\
(10.15)\end{array}$ \\
\hline $\begin{array}{l}\text { WAY_01 } \\
(304 \overline{5 m})\end{array}$ & 7.86 & $\begin{array}{r}\mathrm{n}=1 \\
7.26 \\
(-0.6)\end{array}$ & $\begin{array}{r}\mathrm{n}=591 \\
6.08 \pm 1.85 \\
(-1.78)\end{array}$ & $\begin{array}{r}n=9 \\
5.31 \pm 0.78 \\
(-2.55)\end{array}$ & $\begin{array}{r}\mathrm{n}=178440 \\
9.1 \pm 3.47 \\
(1.24)\end{array}$ & $\begin{array}{r}\mathrm{n}=4210 \\
7.9 \pm 2.48 \\
(0.04)\end{array}$ & $\begin{array}{r}\mathrm{n}=109 \\
6.52 \pm 1.5 \\
(-1.34)\end{array}$ & $\begin{array}{r}\mathrm{n}=288 \\
16.19 \pm 5.76 \\
(8.33)\end{array}$ \\
\hline $\begin{array}{l}\text { ACJ_01 } \\
(3537 \mathrm{~m})\end{array}$ & 7.89 & $\begin{array}{r}\mathrm{n}=1 \\
9.8 \\
(1.91)\end{array}$ & $\begin{array}{r}\mathrm{n}=197 \\
8.85 \pm 1.71 \\
(0.96)\end{array}$ & $\begin{array}{r}n=6 \\
7.45 \pm 0.22 \\
(-0.44)\end{array}$ & $\begin{array}{r}\mathrm{n}=12913 \\
10.07 \pm 3.19 \\
(2.18)\end{array}$ & $\begin{array}{r}\mathrm{n}=530 \\
9.08 \pm 2.59 \\
(1.19)\end{array}$ & $\begin{array}{r}n=41 \\
7.58 \pm 1.31 \\
(-0.31)\end{array}$ & $\begin{array}{r}\mathrm{n}=154 \\
9.29 \pm 5.52 \\
(1.4)\end{array}$ \\
\hline $\begin{array}{l}\text { Across all } \\
\text { elevations }\end{array}$ & $\begin{array}{r}n=9 \\
9.84 \pm 2.5 \\
(\mathrm{n} / \mathrm{a})\end{array}$ & $\begin{array}{r}n=9 \\
9.97 \pm 2.26 \\
(0.13 \pm \\
1.35) \\
\end{array}$ & $\begin{array}{r}\mathrm{n}=5295 \\
10.71 \pm 3.77 \\
(0.26 \pm \\
2.47) \\
\end{array}$ & $\begin{array}{r}\mathrm{n}=74 \\
8.49 \pm 2.79 \\
(-1.49 \pm \\
0.98)\end{array}$ & $\begin{array}{l}\mathrm{n}=1478255 \\
10.28 \pm 3.78 \\
(0.61 \pm 3.36)\end{array}$ & $\begin{array}{r}\mathrm{n}=30040 \\
9.01 \pm 2.98 \\
(-0.5 \pm 2.56)\end{array}$ & $\begin{array}{r}\mathrm{n}=710 \\
7.4 \pm 2.23 \\
(-1.91 \pm \\
1.87)\end{array}$ & $\begin{array}{r}n=1709 \\
17.77 \pm 5.14 \\
(8.88 \pm 5.05)\end{array}$ \\
\hline RMSD & $\mathrm{n} / \mathrm{a}$ & 1.28 & 1.02 & 1.59 & 1.71 & 1.08 & 1.72 & 8.31 \\
\hline
\end{tabular}

871 Table S1. Empirical NPP measurements and a summary of ground-based and RS-CFM model

872 pixel growth rate estimates within and across all plots/elevations shown at multiple spatial scales

873 (plot and landscape) and resolutions (0.01ha, 1ha, and 100ha). NPP units are standardized to

$874 \mathrm{MgC} \mathrm{ha}^{-1} \mathrm{yr}^{-1}$ for all scales and resolutions. For each table entry, the first line (n) designates

875 number of samples (pixels), the second line shows mean \pm standard deviation of $\dot{M}_{\text {pixel }}$ values,

876 and the third line shows mean pixel growth rate deviations $\left(\dot{M}_{\text {pixel }}\right.$ - measured $\left.N P P\right)$ in 
877 parentheses. For across-elevation entries, the third line also provides standard deviations in pixel 878 growth rate deviations.

879

\begin{tabular}{|c|c|c|c|c|c|c|}
\hline Scale & Resolution & Parameter & Estimate & Std. Error & T-value & p-value \\
\hline \multirow[t]{12}{*}{ Plot } & $0.01 \mathrm{ha}$ & Intercept & 10.708 & 0.015 & 711.82 & $<10^{-5}$ \\
\hline & adj. $R 2=0.916$ & LMA & -2.032 & 0.025 & -82.946 & $<10^{-5}$ \\
\hline & $p<10^{-5}$ & $N_{\text {area }}$ & 0.065 & 0.023 & 2.805 & 0.00505 \\
\hline & & $P_{\text {area }}$ & 0.232 & 0.028 & 8.324 & $<10^{-5}$ \\
\hline & & $A_{L}$ & 2.692 & 0.04 & 67.535 & $<10^{-5}$ \\
\hline & & $\mathrm{M}_{\mathrm{L}}$ & 2.466 & 0.027 & 89.972 & $<10^{-5}$ \\
\hline & 1ha & Intercept & 8.494 & 0.064 & 133.522 & $<10^{-5}$ \\
\hline & adj. $R 2=0.962$ & LMA & -1.571 & 0.117 & -13.416 & $<10^{-5}$ \\
\hline & $p<10^{-5}$ & $N_{\text {area }}$ & -0.099 & 0.109 & -0.913 & 0.36465 \\
\hline & & $P_{\text {area }}$ & 0.298 & 0.098 & 3.034 & 0.00342 \\
\hline & & $A_{L}$ & 1.94 & 0.107 & 18.208 & $<10^{-5}$ \\
\hline & & $M_{L}$ & 1.555 & 0.094 & 16.473 & $<10^{-5}$ \\
\hline \multirow[t]{18}{*}{ Landscape } & $0.01 \mathrm{ha}$ & Intercept & 10.281 & 0.001 & 9760.3 & $<10^{-5}$ \\
\hline & adj. $R 2=0.885$ & LMA & -1.81 & 0.001 & -1484.464 & $<10^{-5}$ \\
\hline & $p<10^{-5}$ & $N_{\text {area }}$ & 0.26 & 0.002 & 154.967 & $<10^{-5}$ \\
\hline & & $P_{\text {area }}$ & 0.335 & 0.002 & 172.008 & $<10^{-5}$ \\
\hline & & $A_{L}$ & 3.166 & 0.003 & 987.694 & $<10^{-5}$ \\
\hline & & $M_{L}$ & 3.423 & 0.002 & 1716.488 & $<10^{-5}$ \\
\hline & 1ha & Intercept & 9.014 & 0.005 & 1648.078 & $<10^{-5}$ \\
\hline & adj. $R 2=0.899$ & LMA & -1.446 & 0.006 & -235.41 & $<10^{-5}$ \\
\hline & $p<10^{-5}$ & $N_{\text {area }}$ & 0.066 & 0.009 & 7.26 & $<10^{-5}$ \\
\hline & & $P_{\text {area }}$ & 0.137 & 0.01 & 13.737 & $<10^{-5}$ \\
\hline & & $A_{L}$ & 2.356 & 0.017 & 140.773 & $<10^{-5}$ \\
\hline & & $M_{L}$ & 2.414 & 0.01 & 231.569 & $<10^{-5}$ \\
\hline & 100ha & Intercept & 7.397 & 0.025 & 292.745 & $<10^{-5}$ \\
\hline & adj. $R 2=0.909$ & LMA & -1.132 & 0.029 & -38.4 & $<10^{-5}$ \\
\hline & $p<10^{-5}$ & $N_{\text {area }}$ & -0.228 & 0.039 & -5.858 & $<10^{-5}$ \\
\hline & & $P_{\text {area }}$ & -0.222 & 0.036 & -6.25 & $<10^{-5}$ \\
\hline & & $A_{L}$ & 1.48 & 0.067 & 22.088 & $<10^{-5}$ \\
\hline & & $M_{L}$ & 1.279 & 0.05 & 25.351 & $<10^{-5}$ \\
\hline
\end{tabular}

880

881 Table S2. Multiple regression summary showing the effects of individual model components on

882 RS-CFM pixel growth rate estimates $\left(\dot{M}_{\text {pixel }}\right)$. Regression coefficient estimates are standardized

883 to allow comparison of effect sizes among model components. 


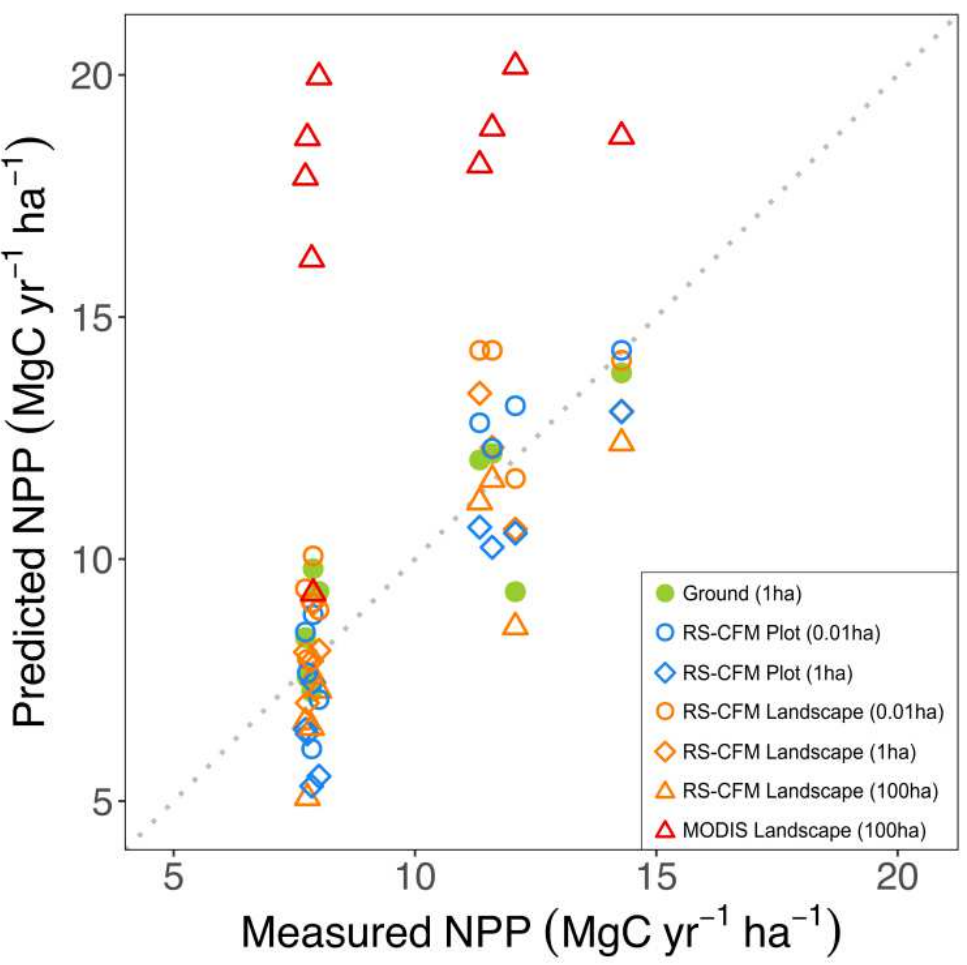

884

885 Figure S1. Deviations between measured and predicted (model) NPP estimates. 


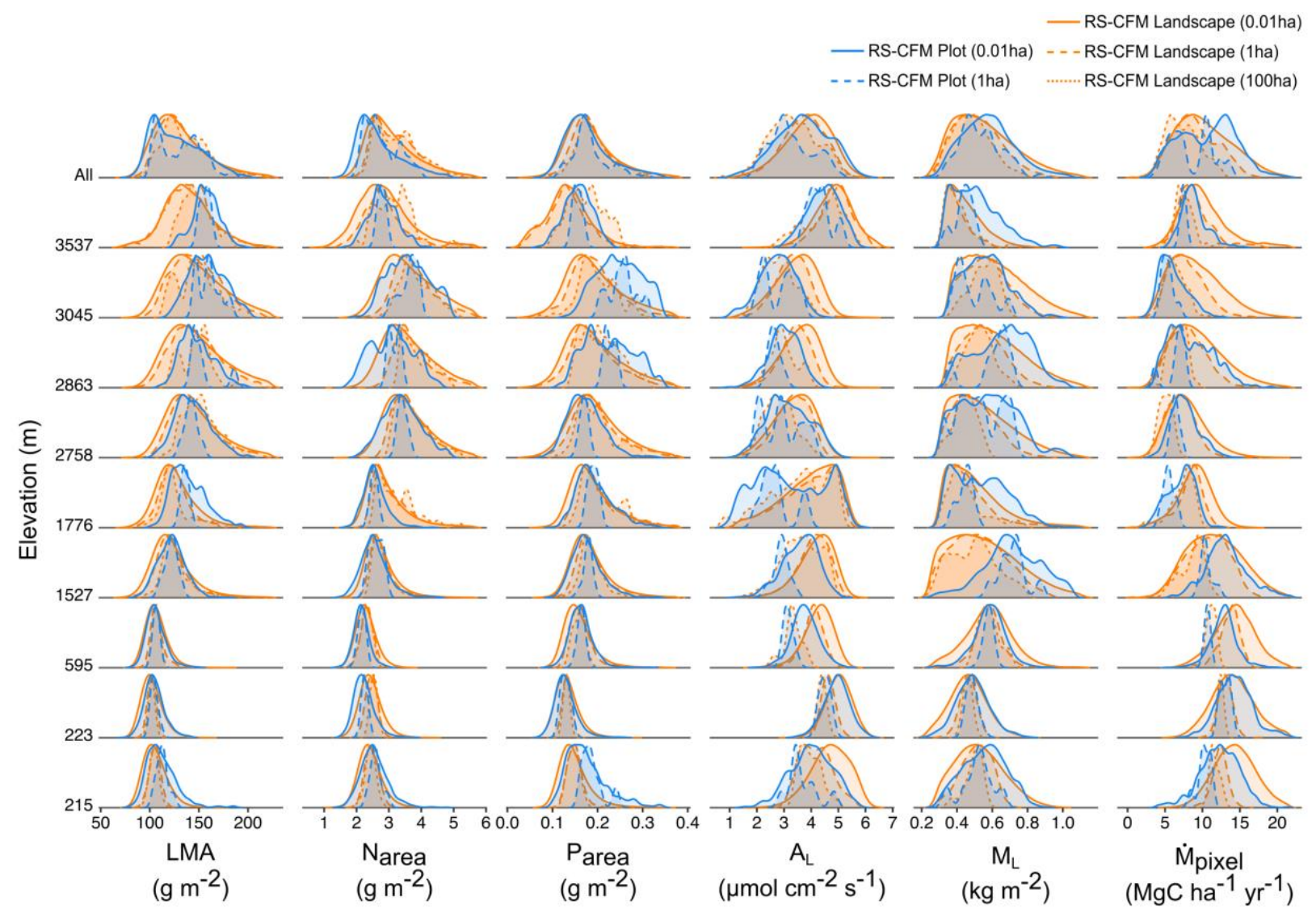

899 Figure S2. Distributions of individual model components and $\dot{M}_{\text {pixel }}$ estimates within and across

900 elevations shown at multiple spatial scales (plot and landscape) and resolutions (0.01ha, 1ha, and

901 100ha). Plot- and landscape-scale data cover a total of 81 and 30,040 hectares, respectively.

902 Variables are leaf mass per unit area (LMA), area-based leaf nitrogen $\left(N_{\text {area }}\right)$ and phosphorus

903 (Parea) content, leaf photosynthetic rate $\left(A_{L}\right)$, total pixel leaf biomass $\left(M_{L}\right)$, and pixel vegetation

904 growth rate $\left(\dot{M}_{\text {pixel }}\right)$.

905

906

907

908

909 


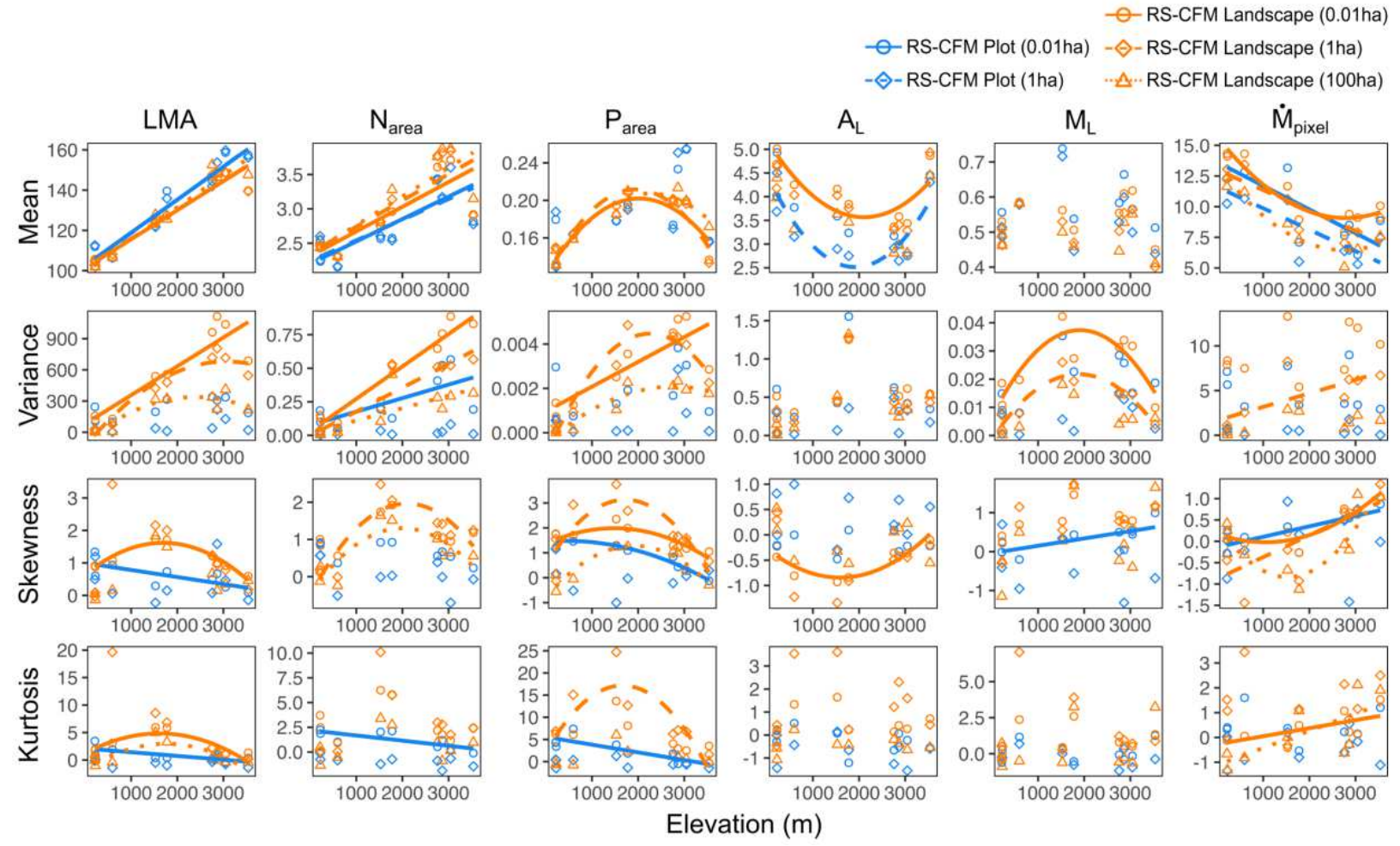

911 Figure S3. Trends in moments of the distributions of individual model components and $\dot{M}_{\text {pixel }}$

912 estimates across elevations shown at multiple spatial scales (plot and landscape) and resolutions

913 (0.01ha, 1ha, and 100ha). Lines designate significant regressions. Both linear and quadratic

914 regressions were tested—linear model fits are shown for cases where both linear and quadratic

915 models produced significant fits and AIC scores differed by less than 4 points. Traits are leaf

916 mass per unit area $(L M A)$, area-based leaf nitrogen $\left(N_{\text {area }}\right)$ and phosphorus $\left(P_{\text {area }}\right)$ content, leaf

917 photosynthetic rate $\left(A_{L}\right)$, total pixel leaf biomass $\left(M_{L}\right)$, and pixel vegetation growth rate $\left(\dot{M}_{\text {pixel }}\right)$. 


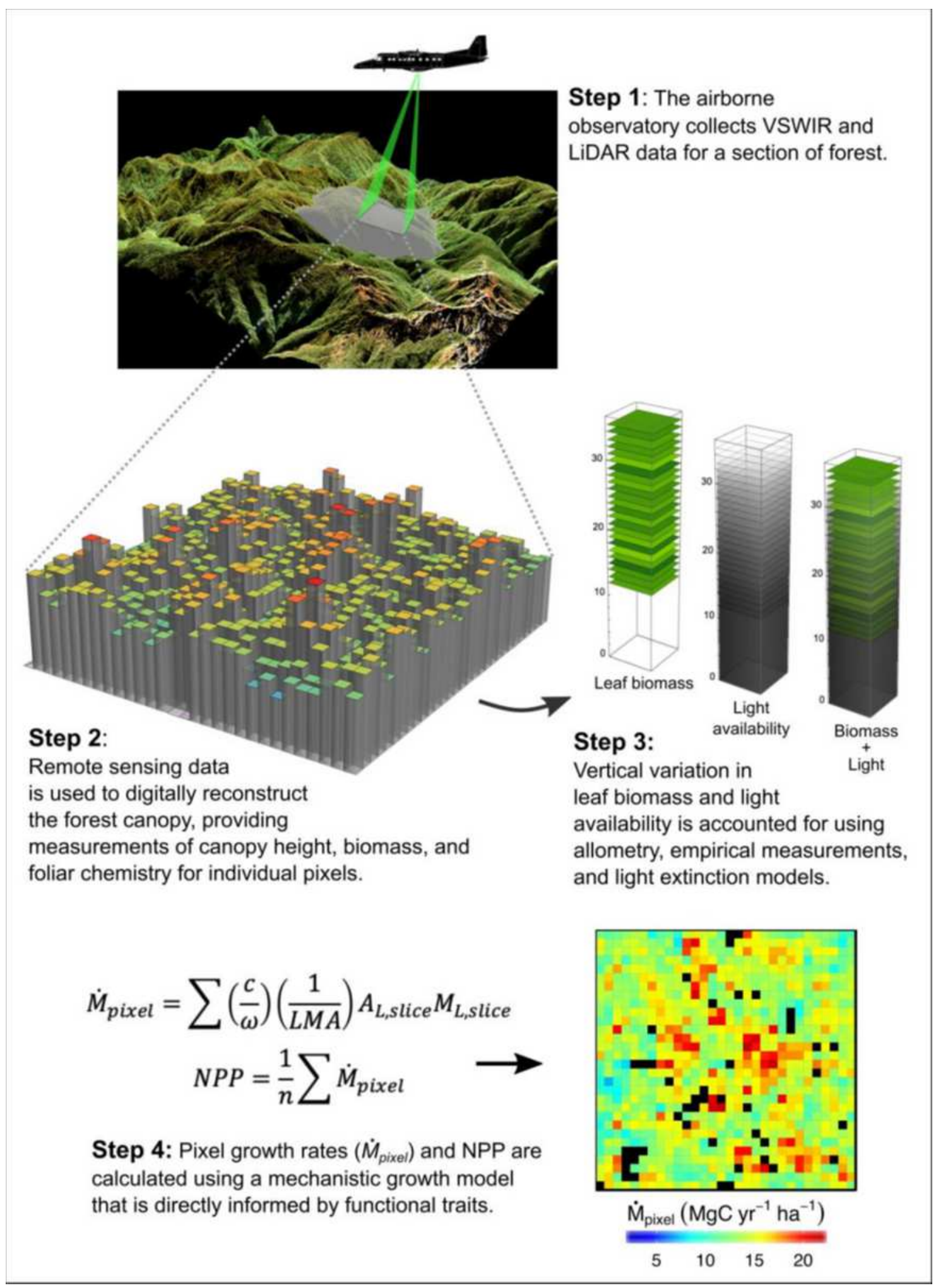

\section{Figure 1}

Step-by-step process for converting remote sensing data into productivity estimates using our trait-based remote sensing canopy functional model (RS-CFM) framework. 


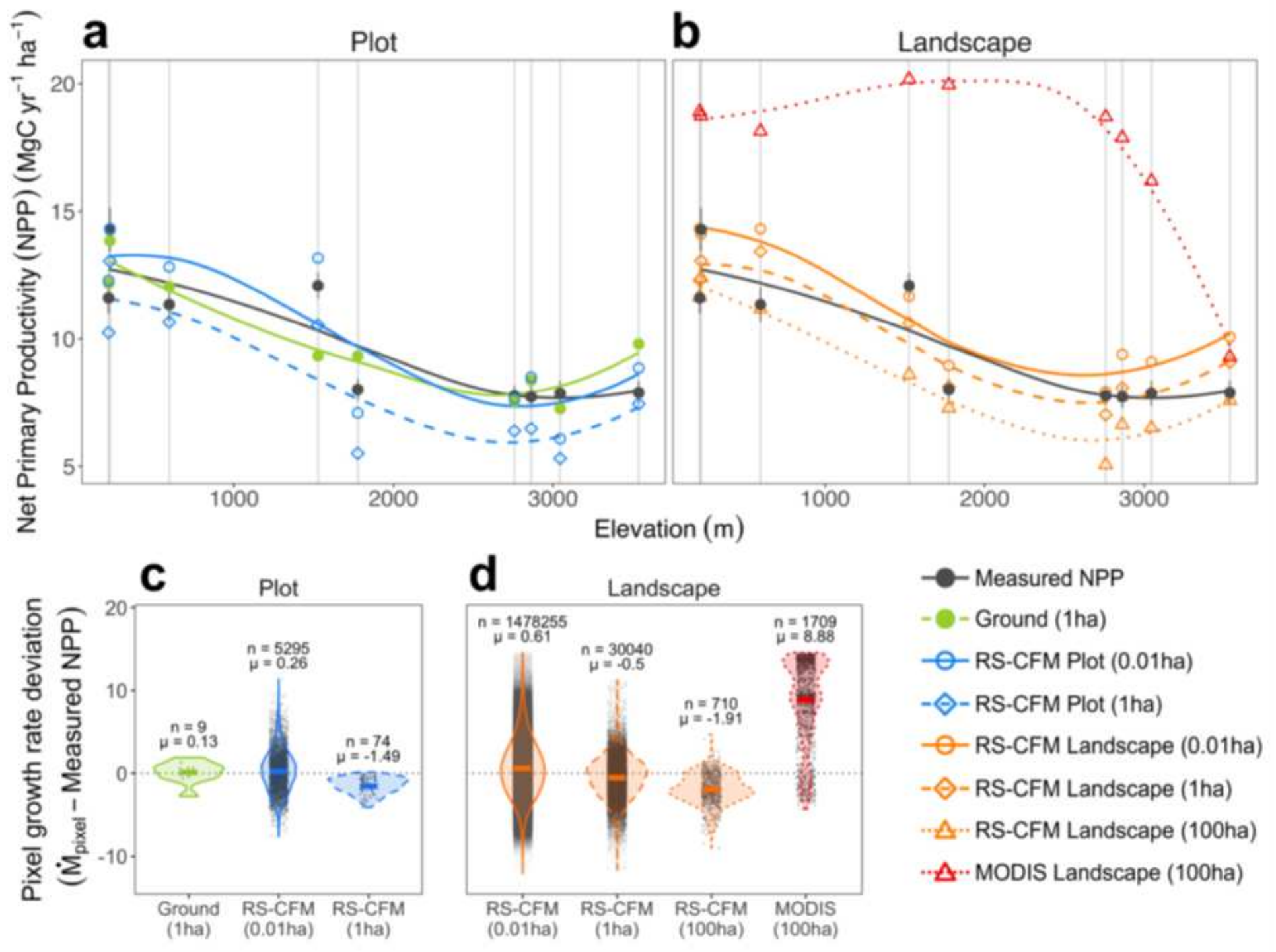

Figure 2

(a-b) Net primary productivity (NPP) and (c-d) individual pixel vegetation growth rate estimates (M囚pixel) from ground-based, airborne remote sensing (RS-CFM), and NASA-MODIS NPP models shown at multiple spatial scales (plot and landscape) and resolutions (0.01ha, 1 ha, and 100ha). 


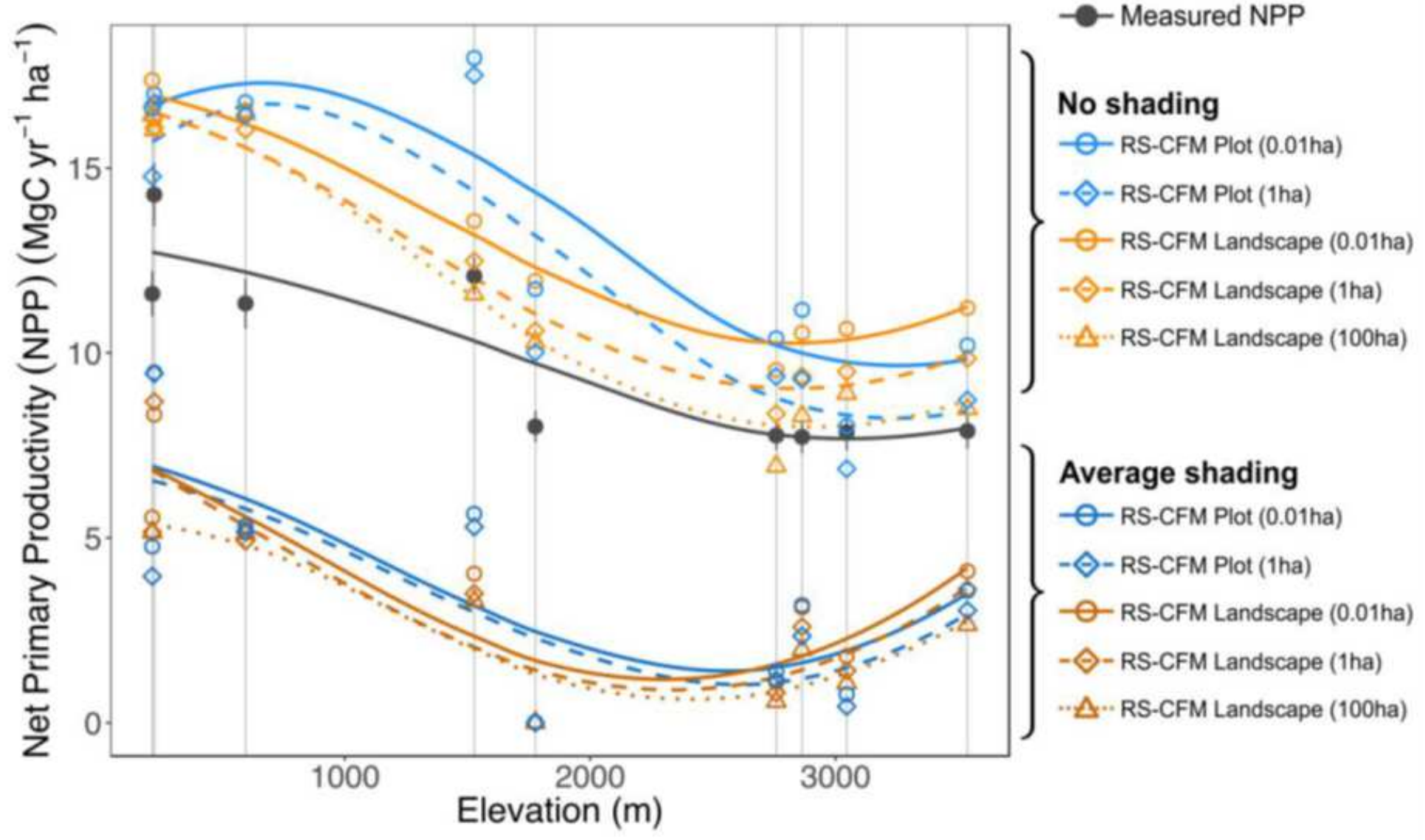

\section{Figure 3}

Remote sensing productivity estimates (RS-CFM) calculated using alternative canopy shading schemes. "No shading" indicates that light is freely available throughout the canopy and "Average shading" indicates that each vertical canopy slice receives the same amount of light equal to the average throughout a given pixel. 
a
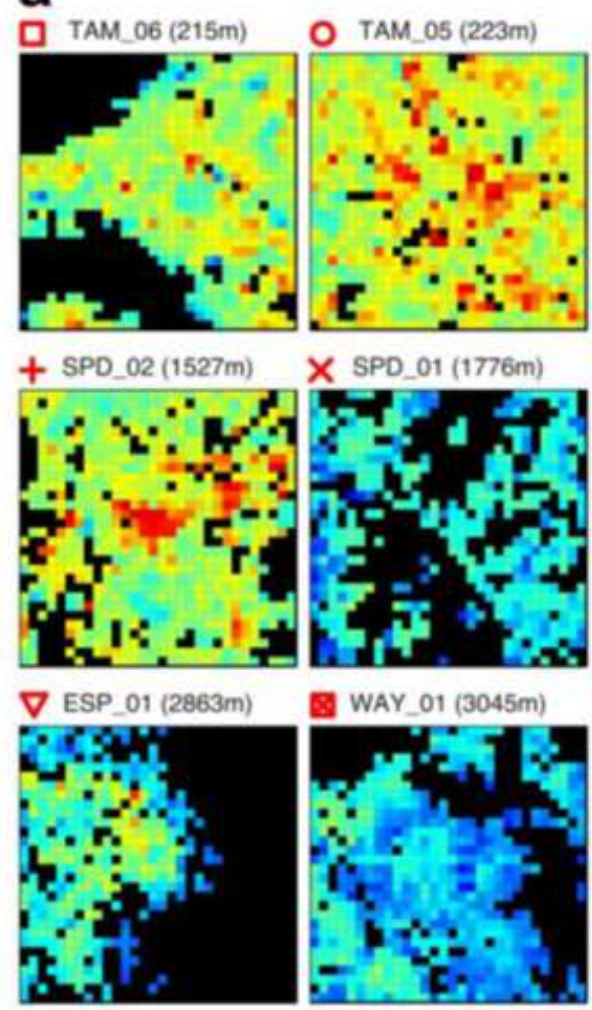

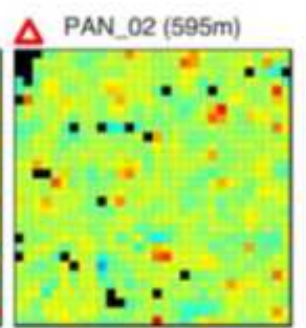

○ TAU_04 (2758m)

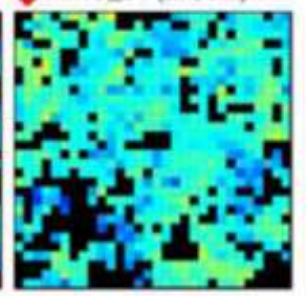

* ACJ_01 (3537m)

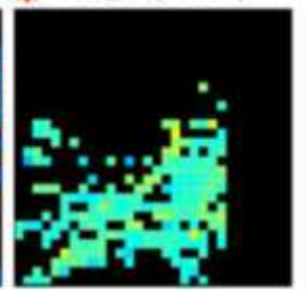

b

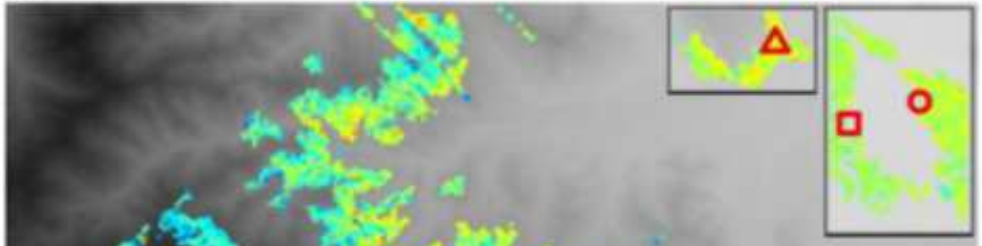

.

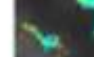

$\lim ^{2}-1,2$
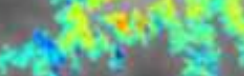

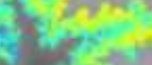
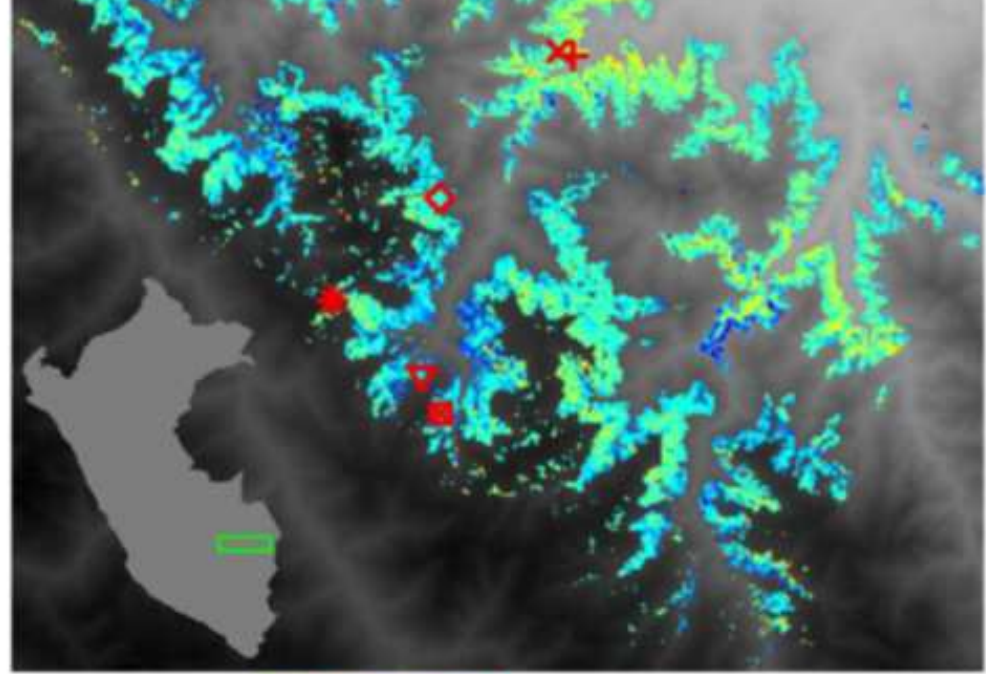

$\dot{\mathrm{M}}_{\text {pixel }}\left(\mathrm{MgC} \mathrm{yr}^{-1} \mathrm{ha}^{-1}\right)$

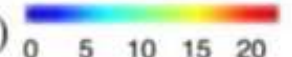

Elevation
2000

\section{Figure 4}

Spatial maps of landscape-scale growth estimates for individual pixels (M®pixel) using our remote sensing canopy functional model (RS-CFM) at (a) 0.01 ha resolution for individual forest plots and (b) 1ha-resolution for 30,040 hectares of forest surrounding the nine focal plots. Boxes in the upper right corner show areas outside the main plot area. Black pixels in plot-level images are no data values. 